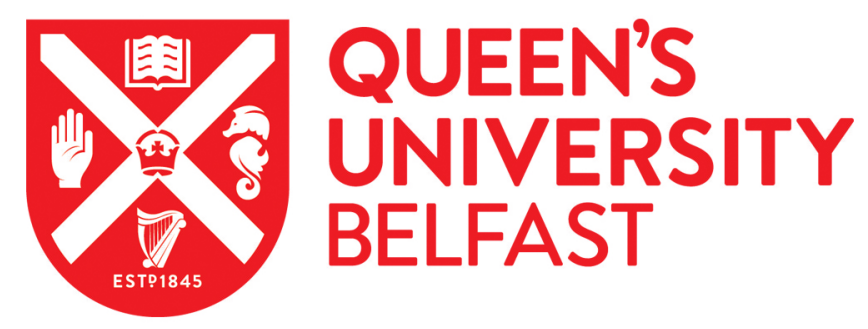

\title{
Understanding the Dual Active Sites of the FeO/Pt(111) Interface and Reaction Kinetics: Density Functional Theory Study on Methanol Oxidation to Formaldehyde
}

Chen, Z., Mao, Y., Chen, J., Wang, H., Li, Y., \& Hu, P. (2017). Understanding the Dual Active Sites of the FeO/Pt(111) Interface and Reaction Kinetics: Density Functional Theory Study on Methanol Oxidation to Formaldehyde. ACS Catalysis, 7, 4281-4290. https://doi.org/10.1021/acscatal.7b00541

Published in:

ACS Catalysis

Document Version:

Peer reviewed version

Queen's University Belfast - Research Portal:

Link to publication record in Queen's University Belfast Research Portal

\section{Publisher rights}

Copyright 2017 ACS. This work is made available online in accordance with the publisher's policies. Please refer to any applicable terms of use of the publisher.

\section{General rights}

Copyright for the publications made accessible via the Queen's University Belfast Research Portal is retained by the author(s) and / or other copyright owners and it is a condition of accessing these publications that users recognise and abide by the legal requirements associated with these rights.

Take down policy

The Research Portal is Queen's institutional repository that provides access to Queen's research output. Every effort has been made to ensure that content in the Research Portal does not infringe any person's rights, or applicable UK laws. If you discover content in the

Research Portal that you believe breaches copyright or violates any law, please contact openaccess@qub.ac.uk. 


\title{
Understanding the dual active sites of $\mathrm{FeO} / \mathrm{Pt}(111)$ interface and reaction kinetics: A density functional theory study on methanol oxidation to formaldehyde
}

Authors: Zongjia Chen, ${ }^{1,2}$ Yu Mao, ${ }^{2}$ Jianfu Chen, ${ }^{1}$ Haifeng Wang, ${ }^{1 *}$ Yadong $\mathrm{Li},{ }^{3 *} \mathrm{P} . \mathrm{Hu},{ }^{1,2^{*}}$

\begin{abstract}
Affiliations:
${ }^{1}$ Key Laboratory for Advanced Materials, Center for Computational Chemistry and Research Institute of Industrial Catalysis, East China University of Science and Technology, Shanghai 200237, China

${ }^{2}$ School of Chemistry and Chemical Engineering, The Queen's University of Belfast, Belfast BT9 5AG, U.K.

${ }^{3}$ Department of Chemistry, Tsinghua University, Beijing 100084, China

*Correspondence to: Peijun Hu (p.hu@qub.ac.uk ), Haifeng Wang (hfwang@ecust.edu.cn) and Yadong Li (ydli@tsinghua.edu.cn)
\end{abstract}

\begin{abstract}
Identifying the active sites and reaction kinetics for a catalytic reaction can provide significant insight to the catalytic systems. By conducting DFT calculations, the catalytic activity of $\mathrm{FeO} / \mathrm{Pt}(111)$ interfacial sites, which is an important class of catalyst with excellent activity, for methanol partial oxidation is carefully examined and compared. The O-H cleavage barrier of methanol is significantly diminished to below $0.1 \mathrm{eV}$ with the aid of interfacial oxygen, which is much lower than that on the $\mathrm{Pt}(111)$ surface $(>0.8 \mathrm{eV})$. The $\mathrm{CH}_{3} \mathrm{O}^{*}$ intermediate can further undergo a C-H bond breaking process to produce formaldehyde via a low barrier $(\sim 0.2 \mathrm{eV})$ at the interfacial Pt sites. Assisted by interfacial Pt-O ensemble, the $\mathrm{O}-\mathrm{H}$ and $\mathrm{C}-\mathrm{H}$ bond cleavage are greatly facilitated, suggesting that the $\mathrm{FeO} / \mathrm{Pt}$ bi-phase system could effectively combine the advantages of two individual phases. To investigate the rate determining steps, a multi-site
\end{abstract}


micro-kinetic model is applied at $\mathrm{FeO} / \mathrm{Pt}$ interface. The results show that the overall rate can be significantly improved by lower the activation energy of interfacial oxygen removal steps. Interestingly, the turnover frequency (TOF) can also be enlarged when increasing the barriers of $\mathrm{O}_{2}$ dissociative adsorption on the Pt flat surface, which is a special feature in multi-phase systems comparing with the mono-phase one. The active site and micro-kinetic studies in our work can provide insights into the development of metal/oxide catalysts for the partial oxidation of methanol or other primary alcohols.

Key words: Density functional theory, $\mathrm{FeO} / \mathrm{Pt}$ interface, methanol partial oxidation, multisites micro-kinetic model, turnover frequency

\section{Introduction}

The oxide-supported transition metal catalysts $\left(\mathrm{TM} / \mathrm{MO}_{\mathrm{x}}\right)$ have been widely used in industrial applications, such as oxide-supported $\mathrm{Ag}$ catalysts for ethylene epoxidation ${ }^{1-2}$ and $\mathrm{CeO}_{2-}$ supported materials in the automotive three-way catalysts (TWC) for emission control. ${ }^{3-5}$ Generally, the catalytic activities can be considerably enhanced by the dispersion of metal particles into oxide supports, ascribing to the increase of specific surface area and active sites ${ }^{6}$ and perhaps the electronic property change of both oxide and metal constituents. Recently, this kind of bi-phase catalytic systems have gained growing attentions..$^{7-8}$ To elucidate the related reaction mechanism on $\mathrm{TM} / \mathrm{MO}_{\mathrm{x}}$-based catalysts, most theoretical work focuses on the study of the mono-phase constituent, in which the catalytic role of metal or oxide has been comprehensively addressed. ${ }^{9}$ Taking $\mathrm{Ag} / \alpha-\mathrm{Al}_{2} \mathrm{O}_{3}$ for ethylene epoxidation as an example, by simply conducting theoretical investigation on silver surface, the reaction mechanism could be acquired and the theoretical work is in well agreement with experimental results, owing to the $\alpha-\mathrm{Al}_{2} \mathrm{O}_{3}$ acting as an inert support to disperse $\mathrm{Ag}$ particles. In addition, the properties of oxide supports have also been extensively investigated. For example, for TWC catalysts, the $\mathrm{CeO}_{2}$ support is regarded as an indispensable component, in which the superb oxygen storage and release properties of ceria oxide have been critically addressed.

The studies of mono-phase component could indeed give significant insight into certain 
catalytic processes; however, some recent work indicates that the neglected interfacial sites play a crucial role in the catalytic activity boost in some oxide/metal bi-phase systems. ${ }^{10-13}$ For example, Shaikhutdinov and co-workers reported that the iron oxide film on $\operatorname{Pt}(111)$ can promote low temperature $\mathrm{CO}$ oxidation. ${ }^{10}$ Furthermore, Bao and co-workers discovered that the exposed ferrous centers at the interface are important active sites contributing to the enhancement of catalytic oxidation on the $\mathrm{FeO} / \mathrm{Pt}$ catalysts. ${ }^{11}$ By fabricating a series of metal/oxide systems, including several Pt, Pd and Ag supported transition metal oxide (Fe, Co, $\mathrm{Ni}, \mathrm{Cu}, \mathrm{Mn}$, et al) and their reversed systems, $\mathrm{Li}$ and co-workers discovered that the interfacial sites are highly active and should be responsible for the activity enhancement of benzyl alcohol partial oxidation. ${ }^{14}$ In such systems, by simply investigating the mono-phase constituent, the promotion effects of interfacial sites might be ignored, resulting in misunderstandings of real catalytic processes. However, the complexity and diversity of interfacial sites largely hindered the study of reaction mechanisms and kinetics.

Recently, a number of ultrathin oxide film-covered metal systems, the so-called inverse model catalysts, have been extensively synthesized and investigated, ${ }^{15-17}$ such as $\mathrm{MO}_{\mathrm{x}}(\mathrm{M}=\mathrm{Fe}, \mathrm{Mn}$, $\mathrm{Ti}, \mathrm{Zr}$ ) on $\mathrm{Pt}(111),{ }^{18-25} \mathrm{MnO}_{\mathrm{x}}, \mathrm{CoO}_{\mathrm{x}}$ and $\mathrm{NiO}_{\mathrm{x}}$ on $\mathrm{Pd}(100),{ }^{26-29} \mathrm{TiO}_{\mathrm{x}}$ and $\mathrm{VO}_{\mathrm{x}}$ on $\mathrm{Au}(111)$ surface. ${ }^{30-31}$ The sophisticated bi-phase images could thus be observed by the microscope technologies, which provide valuable information on the interfacial configuration of the metal/oxide systems. Furthermore, by virtue of density functional theory (DFT) calculations, the electronic properties of interface could be characterized and the reaction mechanism at active sites could be identified, which help us obtain a clear picture of how the interfaces work on catalytic reactions in metal/oxide bi-phase systems. Among the systems of metal-supported ultrathin films, the Pt-supported iron oxide film $(\mathrm{FeO} / \mathrm{Pt})$ has been widely studied. ${ }^{10,}$ 18, 32-34 Using high-resolution scanning tunneling microscopy (STM), Wendt and co-workers uncovered the active sites and boundary structures of pristine, oxidized and reduced $\mathrm{FeO}$ islands on $\mathrm{Pt}(111)$ at atomic-scale. ${ }^{33-34}$ Theoretically, the magnetic and electronic properties of $\mathrm{FeO} / \mathrm{Pt}(111)$ are characterized by Giordano and co-workers. ${ }^{19}$ They also compared the results obtained from $\mathrm{PBE}+\mathrm{U}$ and HSE06 approaches and showed that the DFT $+\mathrm{U}$ approximation 
remains an adequate tool for the studies of the similar metal-supported ultrathin oxide film systems. ${ }^{35}$ Moreover, Li and co-workers investigated the reaction mechanism of CO oxidation at the $\mathrm{FeO} / \mathrm{Pt}(111)$ interface; they found that the oxygen can be readily dissociated at these sites, and the $\mathrm{OH}$ group can further facilitate the oxygen activation and $\mathrm{CO}$ oxidation. ${ }^{11,32}$

Although a great progress has been achieved in the study of metal/oxide systems, many reaction mechanisms and kinetics are still inadequately addressed at the interfacial sites of bi-phase systems. In order to fully understand the catalytic role of interfacial sites, one must answer the following two questions: (i) what is the role of each component in multi-phase systems? (ii) how do the interfacial sites affect the overall reaction kinetics? To provide insight into the metal/oxide systems and address the questions mentioned above, a detailed investigation was carried out on the $\mathrm{FeO}$ ribbon supported $\mathrm{Pt}(111)(\mathrm{FeO} / \mathrm{Pt})$ bi-phase system by using methanol partial oxidation $\left(\mathrm{CH}_{3} \mathrm{OH}+1 / 2 \mathrm{O}_{2} \rightarrow \mathrm{CH}_{2} \mathrm{O}+\mathrm{H}_{2} \mathrm{O}\right)$ as a model reaction. The reasons for the selected system are described as follows: Firstly, the $\mathrm{Pt}(111)$-supported FeO film can be regarded as a simplified model of reverse oxide-supported metal catalyst, which is among the most studied transition metal-supported ultrathin film systems. ${ }^{10,}$ 32-34 The unambiguous interfacial structure can be constructed on account of the extensively previous studies on the $\mathrm{FeO} / \mathrm{Pt}$ system by STM and DFT calculations. ${ }^{33-34}$ Secondly, the theoretical studies of oxidation reactions were limited on $\mathrm{FeO} / \mathrm{Pt}$ and other oxide/metal interfaces. The investigation of alcohol partial oxidation to aldehyde may provide insight into the general rules of oxidation reactions on the oxide/metal bi-phase systems. Thirdly, as the simplest analogues of alcohol, methanol is an ideal model molecule to examine the alcohol partial oxidation process at the bi-phase interface. In addition, formaldehyde is an important product in the methanol decomposition process, ${ }^{36-38}$ which is also an extensively used chemical in industries of adhesives and plastics production. ${ }^{39}$ In the present work, the overall reaction profiles are plotted and compared at different sites of the $\mathrm{FeO} / \mathrm{Pt}$ system, in which the thermodynamically favorable pathway and the active species have been identified. The crucial elementary steps of methanol partial oxidation, including formaldehyde and water formation, are determined and elucidated in a multi-site micro-kinetic framework, ${ }^{40-42}$ with the rate control steps and the role of interfacial 
sites revealed and discussed. The results would provide insight into the design of metal/oxygen systems for the partial oxidation of methanol and other primary alcohols.

\section{Methods and Models}

\subsection{Methods}

The spin-polarised calculations were performed with the Perdew-Burke-Ernzerhof (PBE) ${ }^{43}$ functional within the generalised gradient approximation (GGA) as implemented in the Vienna Ab initio Simulation Package (VASP). ${ }^{44-45}$ The project-augmented wave (PAW) method was used to represent the core-valence electron interaction. ${ }^{46-47}$ The valence electronic states were expanded in plane wave basis sets with a cutoff energy of $450 \mathrm{eV}$. To accurately treat the electron of transition metal oxides, the on-site column repulsion was described for $\mathrm{FeO} / \mathrm{Pt}$ biphase systems by DFT $+\mathrm{U}$ approach ${ }^{48-49}$ with $\mathrm{U}-\mathrm{J}=3 \mathrm{eV}$ for Fe $3 \mathrm{~d}$ orbitals, as used in previous studies. $^{11,35,50}$ To model the methanol partial oxidation on metal mono-phase, a four-layer $p(3 \times 3) \mathrm{Pt}(111)$ slab (Fig. S1) was used (9 Pt atoms in each layer) with $4 \times 4 \times 1 k$-point sampling. For $\mathrm{FeO} / \mathrm{Pt}$ interface simulations, a $\mathrm{FeO}$ ribbon covered $(2 \sqrt{3} \times 5) \operatorname{Pt}(111)$ slab model was applied with $3 \times 2 \times 1 k$-point sampling. The $\mathrm{FeO}$ ribbon consists of three $\mathrm{Fe}$ and three $\mathrm{O}$ columns with Fe atoms coordinated with the top layer of Pt substrate (Fig. 1a). To balance the computational cost and accuracy, a three-layer Pt(111) metal substrate was used (20 Pt atoms in each layer). The bottom two layers of the Pt substrates were fixed, and the other atoms were all relaxed during the structural optimization. A vacuum layer of $15 \AA$ for all calculated models was applied along the $\mathrm{z}$ direction to avoid the interactions between periodically repeated slabs. The atomic positions were optimized using the Broyden-Fletcher-Goldfarb-Shanno minimization scheme until the maximum force of each atom was less than $0.05 \mathrm{eV} / \AA$.

Reaction pathways were searched with a constrained minimization technique. ${ }^{51-53}$ In this approach, we constrain the distance between the reactants in each elementary step and minimize the total energy with respect to all remaining degrees of freedom. This method allows the transition complex to rotate and translate subject to the above constraint. The transition state is verified when (i) all forces on the atoms vanish; and (ii) the total energy is a maximum along 
the reaction coordinate but a minimum with respect to the rest of the degrees of freedom. The vibration frequency calculations were tested for the transition state (TS) structures, which show that the TS structures we located are true saddle points. The adsorption energy of species $\mathrm{X}\left(E_{\mathrm{ad}}\right.$ $(\mathrm{X}))$ is defined as (Eq 1),

$$
E_{\text {ad }}(\mathrm{X})=E_{\mathrm{x} / \text { surf }}-E_{\mathrm{X}}-E_{\text {surf }} \quad(\mathrm{Eq} 1)
$$

in which $E_{\mathrm{x}}, E_{\text {surf, }} E_{\mathrm{x} / \text { surf }}$ are the total energies of adsorbates $\mathrm{X}$ in the gas phase, the clean surface and the optimized adsorbates/surface system, respectively. Thus, a more negative value of $E_{\text {ad }}$ (X) corresponds to a stronger adsorption of species $\mathrm{X}$ on the surface. The activation energy $\left(E_{\mathrm{a}}\right)$ is determined by the energy difference between the transition state and initial state in each corresponding elementary step.

\subsection{Models}

The metal/oxide interfacial structures of reduced and oxidized $\mathrm{FeO}$ islands on $\mathrm{Pt}(111)$ are illustrated in Fig. 1. For the reduced $\mathrm{FeO} / \mathrm{Pt}$ structure, the $\mathrm{FeO} / \mathrm{Pt}$ interface is terminated with $\mathrm{Fe}$ atoms (Fe-FeO/Pt, Fig. 1a), which can act as the active binding sites. The coordinatively unsaturated ferrous site (CUF) shows a strong oxygen binding ability (-1.28 eV heat release) and can readily be oxidized via a low oxygen dissociation barrier $(0.34 \mathrm{eV})$, with $\mathrm{O}-\mathrm{O}$ bond length elongation to $1.77 \AA$ in the transition state (Fig. 1b) from $1.43 \AA$ in the $\mathrm{O}_{2}{ }^{*}$ adsorption state, which is consistent with the previous work of Bao and co-workers who gave an activation energy of $0.42 \mathrm{eV}$ at the PW91 functional level. ${ }^{11}$ After oxygen dissociation, the exposed Fe sites are saturated by adsorbed oxygen, resulting in the O-terminated $\mathrm{FeO} / \mathrm{Pt}$ interface $\left(\mathrm{O}_{2 \mathrm{c}^{-}}\right.$ $\mathrm{FeO} / \mathrm{Pt}$, Fig. 1c). The $\mathrm{O}_{2 \mathrm{c}}$ atom, coordinated with boundary $\mathrm{Fe}$ and substrate $\mathrm{Pt}$, can further migrate to the bridge site of $\mathrm{Fe}$ atoms, leading to the 3-fold coordinated oxygen formation $\left(\mathrm{O}_{3 c^{-}}\right.$ $\mathrm{FeO} / \mathrm{Pt}$, Fig. 1d) ${ }^{33-34}$ It is worth noting that, the total energy difference of the $\mathrm{O}_{3 \mathrm{c}}-\mathrm{FeO} / \mathrm{Pt}$ and $\mathrm{O}_{2 \mathrm{c}}-\mathrm{FeO} / \mathrm{Pt}$ structure is only $0.02 \mathrm{eV}$ thermodynamically, indicating the two structures can both exist. As can be seen in Fig. 1, another O-terminated FeO/Pt interface also exists at the other side of $\mathrm{FeO}$ ribbon, in which oxygen atoms are located at the bridge site of marginal $\mathrm{Fe}$ atoms without bonding with substrate $\mathrm{Pt}$ atoms (denotes as $\mathrm{Obri}-\mathrm{FeO} / \mathrm{Pt}$, Fig. 1d, e). According to 
previous work by Wendt and co-workers, ${ }^{33-34}$ the $\mathrm{FeO} / \mathrm{Pt}$ interface can undergo the transformation from $\mathrm{Fe}-\mathrm{FeO} / \mathrm{Pt}$ into the $\mathrm{O}_{3 \mathrm{c}}-\mathrm{FeO} / \mathrm{Pt}$ structure and further to the stable Obri$\mathrm{FeO} / \mathrm{Pt}$ boundary (Fig. 1e) during the oxygenation process. Thus, both the Fe- and O-terminated $\mathrm{FeO} / \mathrm{Pt}$ interfaces $\left(\mathrm{O}_{2 \mathrm{c}}-\mathrm{FeO} / \mathrm{Pt}, \mathrm{O}_{3 c}-\mathrm{FeO} / \mathrm{Pt}\right.$ and $\mathrm{O}$ bri-FeO/Pt $)$ are considered in our study.

\section{Results and Discussion}

\subsection{Methanol adsorption}

To compare the binding abilities of methanol at interfacial sites, the methanol adsorption energies were calculated at a variety of sites of $\mathrm{FeO} / \mathrm{Pt}$ interface, including the $\mathrm{Pt}$ and $\mathrm{Fe}$ sites at $\mathrm{O}$ - and $\mathrm{Fe}$-terminated $\mathrm{FeO} / \mathrm{Pt}$ interfaces. The detailed configurations of methanol adsorption are illustrated in Fig. 2. At the Fe- FeO/Pt interface, the CUF sites (Fig. 2a) are the primary binding positions for methanol adsorption, which gives an energy release of $0.70 \mathrm{eV}$. By contrast, the Pt sites show a weaker binding strength with methanol (-0.21 eV, Fig. 2b), close to the result obtained on $\operatorname{Pt}(111)(-0.23 \mathrm{eV})$. Under oxygen-rich conditions, the CUF sites can be readily oxidized, leading to the formation of O-terminated $\mathrm{FeO} / \mathrm{Pt}$ interface, owing to a low activation barrier $(0.36 \mathrm{eV})$ for the dissociation of oxygen.

On $\mathrm{O}_{2 \mathrm{c}}-\mathrm{FeO} / \mathrm{Pt}$ interface (Fig. 2c), the methanol adsorption is exothermic by $0.61 \mathrm{eV}$ at the $\mathrm{Fe}$ site, showing no obvious difference from the CUF site $(-0.70 \mathrm{eV})$. Surprisingly, the methanol adsorption is dramatically enhanced $(-0.76 \mathrm{eV})$ at the Pt site of $\mathrm{O}_{2 \mathrm{c}}-\mathrm{FeO} / \mathrm{Pt}$ (Fig. 2d), stronger by over $0.5 \mathrm{eV}$ than those at the same sites of $\mathrm{Fe}-\mathrm{FeO} / \mathrm{Pt}$ and $\mathrm{Pt}(111)$ surfaces. The result shows that the interfacial $\mathrm{Pt}$ and $\mathrm{O}$ atoms (denote as $\mathrm{Pt}-\mathrm{O}$ ensemble) can synergistically promote the methanol adsorption by providing adsorbed sites and forming hydrogen bond with methanol. Similarly, the Pt-O ensemble of $\mathrm{O}_{3 c}-\mathrm{FeO} / \mathrm{Pt}$ interface is also highly active for methanol adsorption ( $0.83 \mathrm{eV}$ exothermic), with a hydrogen bond formed and the interfacial oxygen moved away from the Fe-Fe bridge site (Fig. 2e). The other side of $\mathrm{O}_{3 \mathrm{c}}-\mathrm{FeO}$ ribbon, terminated by bridge oxygen $\mathrm{Obri}(\mathrm{Obri}-\mathrm{FeO} / \mathrm{Pt}$, Fig. 2f), was evaluated for the methanol adsorption. The binding strength of methanol is still high $(-0.89 \mathrm{eV}$, Table S3) at the Pt-O ensemble of Obri$\mathrm{FeO} / \mathrm{Pt}$ interface, showing the interfacial Pt-O ensemble could indeed improve the methanol 
adsorption in comparison with the mono-phase Pt sites.

The methanol adsorption energies at the above sites are plotted in Fig. 2g, which shows the binding strength of methanol can be greatly enhanced at the Pt-O ensembles of O-FeO/Pt interfaces. It can be ascribed to the formation of strong hydrogen bond between interfacial oxygen and the hydrogen of hydroxyl in methanol. The weakest methanol binding strength is found on the $\mathrm{Pt}(111)$ surface while both the Fe- and O-terminated $\mathrm{FeO} / \mathrm{Pt}$ interfaces could provide active sites (Fe or $\mathrm{Pt}$ atoms) for methanol adsorption. It indicates the methanol would be accumulated at the $\mathrm{FeO} / \mathrm{Pt}$ interface under experimental condition, which is consistent with the previous results of alcohol analogues (benzyl alcohol) adsorption at $\mathrm{FeO} / \mathrm{Pt}$ interface. ${ }^{14}$

\subsection{Methanol decomposition at Fe-FeO/Pt interface}

The reaction pathways of $\mathrm{CH}_{3} \mathrm{OH}$ decomposition have been comprehensively investigated on platinum surfaces in previous studies. ${ }^{36-37}$ The formaldehyde formation can start with O-H bond scission to remove the first hydrogen, then followed by the $\mathrm{C}-\mathrm{H}$ bond cleavage to remove the second hydrogen (pathway 1, Scheme 1). Alternatively, the C-H bond cleavage can firstly occur, leading to $\mathrm{CH}_{2} \mathrm{OH}^{*}$ intermediate formation; then the formaldehyde can be produced by the subsequent $\mathrm{O}-\mathrm{H}$ bond dissociation of $\mathrm{CH}_{2} \mathrm{OH}^{*}$ species (pathway 2, Scheme 1).

In this work, DFT calculations were initially carried out at the $\mathrm{Fe}-\mathrm{FeO} / \mathrm{Pt}$ interface, where the CUF sites are highly active for methanol adsorption $(-0.70 \mathrm{eV})$. In pathway 1 , the first hydrogen striping occurs through the transition state (TS1, Fig. 3b) with an O-H distance of $1.23 \AA$ in methanol. The hydrogen can be transferred to a nearby 3 -fold coordinated oxygen $\left(\mathrm{O}_{\text {latt }}\right)$ in the $\mathrm{FeO}$ ribbon, resulting in an $\mathrm{O}_{\text {latt- }} \mathrm{H}$ distance of $1.22 \AA$ in the TS. The O-H cleavage step is slightly endothermic by $0.15 \mathrm{eV}$ via a $0.46 \mathrm{eV}$ barrier, leading to the formation of $\mathrm{O}_{\text {latt }} \mathrm{H}$ and methoxyl $\left(\mathrm{CH}_{3} \mathrm{O}^{*}\right)$ intermediates (IM, Fig. 3c) at Fe site. The second hydrogen cleavage is occurred by $\mathrm{C}-\mathrm{H}$ bond breaking of $\mathrm{CH}_{3} \mathrm{O}^{*}$ species, in which the hydrogen can be transferred to another nearby Olatt via the TS2 (Fig. 3d). The C-H dissociation step is endothermic by $0.18 \mathrm{eV}$, while the activation barrier is much higher than that of $\mathrm{O}-\mathrm{H}$ cleavage (1.16 vs. $0.46 \mathrm{eV})$, suggesting that the $\mathrm{C}-\mathrm{H}$ breaking process could hardly proceed. In pathway 2 , the hydrogen 
transfers from carbon to $\mathrm{O}_{\text {latt }}$ as a start, in which the $\mathrm{C}-\mathrm{H}$ bond is elongated to $1.54 \AA$ in the transition state (TS1', Fig. 3e). The C-H bond breaking step is endothermic by $0.86 \mathrm{eV}$ via a large activation energy $(1.63 \mathrm{eV})$, suggesting that this process should be difficult to proceed. Then a hydrogen bond can be formed between another Olatt and the hydrogen of $\mathrm{CH}_{2} \mathrm{OH}^{*}$ species (IM', Fig. 3f). The subsequent $\mathrm{O}-\mathrm{H}$ bond cleavage of $\mathrm{CH}_{2} \mathrm{OH}^{*}$ occurs by hydrogen transfer to $\mathrm{O}_{\text {latt }}$ via transition state TS2' (Fig. 3g). The O-H bond breaking is exothermic by 0.89 $\mathrm{eV}$ and undergoes a low activation energy $(0.10 \mathrm{eV})$.

After formation of two Olatt $\mathrm{H}$, the formaldehyde is produced and adsorbed at the Fe site via oxygen atom (Fig. 3h). The further desorption of formaldehyde is endothermic by $0.83 \mathrm{eV}$, leading to the formation of $\mathrm{O}_{\text {latt }} \mathrm{H}$ adsorbed $\mathrm{FeO} / \mathrm{Pt}$ structure. One can see from Table 1 that the $\mathrm{C}-\mathrm{H}$ bond cleavage apparently undergoes a much higher activation energy (over $1 \mathrm{eV}$ ) than $\mathrm{O}-$ $\mathrm{H}$ bond breaking (under $0.5 \mathrm{eV}$ ) in the above two pathways. Thus, at CUF site of the $\mathrm{Fe}-\mathrm{FeO} / \mathrm{Pt}$ interface, C-H bond dissociation should be the rate determining step for formaldehyde formation. Additionally, the overall activation energy of pathway 1 is lower than that of pathway 2 , suggesting the former pathway is kinetically favored.

\subsection{Methanol decomposition at $\mathrm{O}-\mathrm{FeO} / \mathrm{Pt}$ interface}

The Fe-FeO/Pt interface could be oxidized and transformed to the O-terminated interface under experimental condition, as discussed in the model construction section. To uncover the catalytic activity of the oxidized $\mathrm{FeO} / \mathrm{Pt}$ interface, detailed calculations were performed on the reaction pathways at the $\mathrm{O}_{2 c}-\mathrm{FeO} / \mathrm{Pt}$ interface and other two relevant oxygen edges $\left(\mathrm{O}_{3 c}\right.$ - and $\mathrm{O}$ bri- $\mathrm{FeO} / \mathrm{Pt}$ interfaces). In pathway 1, the hydrogen is transferred from the oxygen of methanol to the interfacial oxygen $\left(\mathrm{O}_{2 c}\right)$ via transition state TS1 (Fig. 4b). Remarkably, the activation barrier of $\mathrm{O}-\mathrm{H}$ bond cleavage is diminished to $0.04 \mathrm{eV}$, indicating that the hydrogen transfer process can readily occur at the $\mathrm{O}_{2} \mathrm{c}-\mathrm{FeO} / \mathrm{Pt}$ interface. The $\mathrm{CH}_{3} \mathrm{O}$ * intermediate (IM, Fig. 4c) adsorbs at a Pt site of $\mathrm{O}_{2 \mathrm{c}}-\mathrm{FeO} / \mathrm{Pt}$, and then the $\mathrm{CH}_{2} \mathrm{O}$ * is formed via the $\mathrm{C}-\mathrm{H}$ bond scission. In the transition state (TS2, Fig. 4d), the $\mathrm{C}-\mathrm{H}$ bond of $\mathrm{CH}_{3} \mathrm{O}$ * is elongated to $1.38 \AA$, and then the hydrogen could transfer to another Pt site, which is similar to the case on the $\operatorname{Pt}(111)$ surface (Fig. S1e). 
The $\mathrm{C}-\mathrm{H}$ cleavage step is exothermic by $0.42 \mathrm{eV}$ with a not high barrier $(0.17 \mathrm{eV})$. The subsequent migration of dissociated hydrogen to interfacial oxygen will lead to an energy release by $-0.79 \mathrm{eV}$. In pathway 2 , the hydrogen atom transfers from carbon to $\mathrm{Pt}$ atom as a start, in which the C-H bond distance is elongated to $1.45 \AA$ in the TS structure (TS1', Fig. 4e). The activation energy of $\mathrm{C}-\mathrm{H}$ cleavage is $0.68 \mathrm{eV}$, close to the value at $\mathrm{Pt}(111)(0.67 \mathrm{eV})$. The possibility of C-H cleavage assisted by interfacial oxygen is also tested; however, its activation energy is higher than direct $\mathrm{C}-\mathrm{H}$ bond breaking at $\mathrm{Pt}$ sites. The $\mathrm{CH}_{2} \mathrm{OH}^{*}$ intermediate adsorbs at two neighboring Pt atoms via $\mathrm{C}$ and $\mathrm{O}$, and forms a hydrogen bond with an interfacial $\mathrm{O}_{2 \mathrm{c}}$ (IM', Fig. 4f). Subsequently, the hydrogen of hydroxyl could transfer to $\mathrm{O}_{2 \mathrm{c}}$ with a low activation energy (0.03 eV, Fig. 4g). An OH-terminated FeO/Pt interface (OH-FeO/Pt) would be gradually formed during the methanol decomposition and formaldehyde desorption process ( $0.30 \mathrm{eV}$ endothermic). Notably, the interfacial hydroxyl should be removed to provide free sites for oxygen chemisorption and eventually restore the interfacial structure.

The $\mathrm{O}-\mathrm{H}$ bond cleavage step was also investigated on the other two O-terminated $\mathrm{FeO} / \mathrm{Pt}$

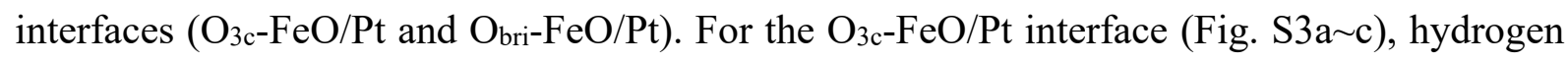
bond could be formed between methanol and interfacial $\mathrm{O}_{3 c}$, which will make the $\mathrm{O}_{3 c}$ atom move to the 2-fold coordinated site (like $\mathrm{O}_{2 \mathrm{c}}$ ). Likewise, at the $\mathrm{O}_{\text {bri }} \mathrm{FeO} / \mathrm{Pt}$ interface (Fig. S3d f), a hydrogen bond could also be formed between methanol and interfacial oxygen ( $\left.\mathrm{Obri}_{\mathrm{br}}\right)$. Assisted by interfacial $\mathrm{O}_{3 c}$ and $\mathrm{O} b r i$, the $\mathrm{O}-\mathrm{H}$ bond cleavage of methanol would be readily proceeded via a very low barrier (below $0.1 \mathrm{eV}$ ), which is in consistent with the results obtained at the $\mathrm{O}_{2 \mathrm{c}}-\mathrm{FeO} / \mathrm{Pt}$ interface. The result suggests that the interfacial oxygen of the $\mathrm{FeO} / \mathrm{Pt}$ interface could generally act as an active site for the striping of hydrogen from the hydroxyl of methanol, which is well consistent with our previous work that the O-H bond of benzyl alcohol is effectively activated by the interfacial oxygen of $\mathrm{FeO} / \mathrm{Pt}$ interface. ${ }^{14}$

As the formaldehyde formation proceeds, the $\mathrm{O}-\mathrm{FeO} / \mathrm{Pt}$ interface will be gradually transformed to $\mathrm{OH}$-terminated $\mathrm{FeO} / \mathrm{Pt}$ boundary. It is notable that the hydroxyl removal would be hindered if the $\mathrm{OH}$ binding strength is too strong at the interfacial sites, which will block the overall catalytic cycle. For simplicity, the energy of oxygen vacancy $\left(\mathrm{O}_{\mathrm{v}}\right)$ formation $\left(\mathrm{O}^{*} \rightarrow 1 / 2 \mathrm{O}_{2}+*\right)$ 
was calculated in order to estimate the binding strength of hydroxyl species. Generally, a higher EOv (stronger $\mathrm{O}^{*}$ binding) suggests a more difficult $\mathrm{O}^{*}$ removal process $\left(\mathrm{O}^{*} \rightarrow 1 / 2 \mathrm{O}_{2}\right.$ or $\mathrm{O}^{*}+$ $\left.\mathrm{H}_{2} \rightarrow \mathrm{H}_{2} \mathrm{O}+*\right) .{ }^{54-56}$ At the $\mathrm{O}_{2 \mathrm{c}}$ and $\mathrm{O}_{3 \mathrm{c}}-\mathrm{FeO} / \mathrm{Pt}$ interfaces, the $\mathrm{O}_{\mathrm{v}}$ formation energies are only around $1 \mathrm{eV}$. However, the $\mathrm{O}_{\mathrm{v}}$ formation is much more difficult at the $\mathrm{Obri}_{\mathrm{i}} \mathrm{FeO} / \mathrm{Pt}$ interface $(1.90 \mathrm{eV})$, suggesting that the further $\mathrm{OH}$ removal would be harder. The total energy of $\mathrm{O}_{2 \mathrm{c}} \mathrm{H}-$ $\mathrm{FeO} / \mathrm{Pt}$ interface is lower than $\mathrm{O}_{3 \mathrm{c}} \mathrm{H}-\mathrm{FeO} / \mathrm{Pt}$ by $0.42 \mathrm{eV}$, ascribing to the formation of hydrogen bonds between the neighboring hydroxyl at the $\mathrm{O}_{2 \mathrm{c}}-\mathrm{FeO} / \mathrm{Pt}$ interface (Fig. S4). Thus, the $\mathrm{O}_{2 \mathrm{c}} \mathrm{H}-$ $\mathrm{FeO} / \mathrm{Pt}$ interface is most likely to be formed under the reaction condition.

\subsection{Activity comparison between interface and mono-phase sites}

To compare the reaction activities of interface and mono-phase sites, we further carried out calculations on $\mathrm{Pt}(111)$. On the $\mathrm{Pt}(111)$ surface, the methanol decomposition can start with the $\mathrm{O}-\mathrm{H}$ bond scission to remove the first hydrogen via an activation energy of $0.87 \mathrm{eV}$, and then the second hydrogen can be removed by the $\mathrm{C}-\mathrm{H}$ bond activation via a $0.24 \mathrm{eV}$ barrier with $0.34 \mathrm{eV}$ heat releasing in pathway 1 . Alternatively, the $\mathrm{C}-\mathrm{H}$ bond cleavage can firstly occur via an activation energy of $0.67 \mathrm{eV}$, then followed by the $\mathrm{O}-\mathrm{H}$ bond dissociation via a $0.81 \mathrm{eV}$ reaction barrier in pathway 2 . The reaction profiles are illustrated in Fig. 5. One can see that the reaction profile of pathway 2 is under that of pathway 1 on the $\operatorname{Pt}(111)$ surface, implying that the $\mathrm{C}-\mathrm{H}$ bond breaking is preferred to start the methanol decomposition. Besides, the $\mathrm{O}-\mathrm{H}$ cleavage step, having a much higher barrier (over $0.8 \mathrm{eV}$ ) than the $\mathrm{C}-\mathrm{H}$ breaking step in both pathways, could be regarded as the main obstacle that prevents the methanol decomposition. In contrast, at the $\mathrm{O}-\mathrm{FeO} / \mathrm{Pt}$ interface, the interfacial oxygen species, including $\mathrm{O}_{2 \mathrm{c}}, \mathrm{O}_{3 \mathrm{c}}$ and $\mathrm{O}_{b r i}$, show a stronger attraction of hydrogen and are all highly active for the hydrogen striping from the hydroxyl of methanol, in which the activation energies of $\mathrm{O}-\mathrm{H}$ bond breaking are remarkably reduced to below $0.1 \mathrm{eV}$ with the aid of the interfacial oxygen. For the $\mathrm{C}-\mathrm{H}$ bond cleavage, the kinetic barriers show little difference from those results obtained on the $\operatorname{Pt}(111)$ surface. One can see from the energy profile (Fig. 5) that the C-H bond breaking needs to overcome a higher barrier than the $\mathrm{O}-\mathrm{H}$ bond cleavage in both pathways; and pathway 1, which starts with the $\mathrm{O}-\mathrm{H}$ bond cleavage, should be a favorable pathway for methanol decomposition 
at the $\mathrm{O}-\mathrm{FeO} / \mathrm{Pt}$ interface. Thus, by comparing the reaction profiles on the $\mathrm{Pt}(111)$ surface and $\mathrm{O}-\mathrm{FeO} / \mathrm{Pt}$ interface, the interfacial Pt-O ensemble obviously showing more advantage than mono-phase Pt sites in methanol decomposition.

Regarding FeO oxide, we could estimate its activity from the results at the $\mathrm{Fe}-\mathrm{FeO} / \mathrm{Pt}$ surface, because the local structure of $\mathrm{FeO}$ ribbon is close to the $\mathrm{FeO}(111)$ mono-layer, and the $\mathrm{Pt}$ sites were not involved in the calculation. Actually, the interfacial Fe sites of $\mathrm{Fe}-\mathrm{FeO} / \mathrm{Pt}$ should be more active than those of $\mathrm{FeO}(111)$, because the unsaturated $\mathrm{Fe}$ atom could provide an appropriate binding site for methanol adsorption. When the Fe atom is saturated by oxygen (Fig. 2c), the binding strength of methanol would be weakened in comparison with the CUF site (Fig. 2a). The $\mathrm{O}_{\text {latt }}$ of $\mathrm{FeO}$ ribbon, exhibiting similar local configuration of the oxygen on the $\mathrm{FeO}(111)$ surface, could also abstract the hydrogen of hydroxyl in methanol; however, the kinetic barriers are higher than those at the interfacial Pt-O ensemble. Furthermore, a much higher activation energy (over $1 \mathrm{eV}$, Table 1) is required for the $\mathrm{C}-\mathrm{H}$ bond breaking, indicating that the overall reaction rate should be slower at $\mathrm{Fe}$ sites of $\mathrm{FeO}$ ribbon. It is also noteworthy that the removal of adsorbed $\mathrm{O}_{1 a t t} \mathrm{H}$ on the $\mathrm{FeO}$ mono-phase is required to complete the catalytic cycle, which is difficult to proceed ( $\sim 2.9 \mathrm{eV}$ needed to form oxygen vacancies). Therefore, the FeO monophase, alike the FeO ribbon, is predicted to be inert for catalyzing the methanol decomposition. Clearly, the mono-phases of $\mathrm{FeO}$ or Pt could not effectively promote the reaction of methanol decomposition, while the interfacial $\mathrm{Pt}-\mathrm{O}$ ensemble of $\mathrm{FeO} / \mathrm{Pt}$ show a much better performance.

\subsection{Formation of oxygen vacancy and water}

To complete the catalytic cycle, the interfacial hydroxyl should be removed to provide free sites for subsequent oxygen adsorption and dissociation. To evaluate the hydroxyl coverage effect at the interfacial sites, calculations were carried out at the $\mathrm{OH}$-terminated $\mathrm{FeO} / \mathrm{Pt}$ interface for overall methanol partial oxidation. Pathway 1 was regarded as a more favorable route and its elementary steps were investigated in this part, considering the overall barrier in pathway 1 is lower than that in pathway 2 (over $0.6 \mathrm{eV}$ ). After the formaldehyde formation and desorption, the $\mathrm{OH}^{*}$ species can be removed with the aid of adsorbed hydrogen $\left(\mathrm{OH}^{*}+\mathrm{H}^{*} \rightarrow \mathrm{H}_{2} \mathrm{O}+2^{*}\right)$, 
resulting in a water molecule desorption and an oxygen vacancy formation (denoted as $\mathrm{O}_{\mathrm{v}}$ ) at the $\mathrm{FeO} / \mathrm{Pt}$ interface.

The reaction profile of the catalytic cycle is plotted with detailed structures depicted in Fig. 6, in which the reaction starts with oxygen adsorption (1.40 eV exothermic) at the interfacial free site $\left(\mathrm{O}_{\mathrm{v}}\right)$. The methanol adsorption is exothermic by $0.55 \mathrm{eV}$ at the $\mathrm{OH}-\mathrm{FeO} / \mathrm{Pt}$ interface with a 2/3 hydroxyl coverage. The binding strength of methanol is weaker at the $\mathrm{OH}-\mathrm{FeO} / \mathrm{Pt}$ interface than $\mathrm{O}-\mathrm{FeO} / \mathrm{Pt}$ interface by $0.21 \mathrm{eV}$, which is probably due to the fact that the formed hydrogen bond is weakened at the hydrogen-rich interface. The methanol decomposition starts with O-H scission, in which the $\mathrm{O}-\mathrm{H}$ bond distance elongates to $1.34 \AA$ in the transition state. Likewise, the $\mathrm{O}-\mathrm{H}$ bond breaking barrier is not high (below $0.1 \mathrm{eV}$ ) in the aid of interfacial oxygen. In the subsequent step, the $\mathrm{C}-\mathrm{H}$ bond scission of $\mathrm{CH}_{3} \mathrm{O}$ * gives an activation energy by $0.22 \mathrm{eV}$ at the $\mathrm{OH}-\mathrm{FeO} / \mathrm{Pt}$ interface, close to the values at $\mathrm{O}_{2 \mathrm{c}}-\mathrm{FeO} / \mathrm{Pt}$ interface and $\mathrm{Pt}(111)(0.17,0.24 \mathrm{eV}$, respectively). The dissociated hydrogen $\left(\mathrm{H}^{*}\right)$ can migrate to the $\mathrm{FeO} / \mathrm{Pt}$ interface and attack the interfacial hydroxyl. Then an $\mathrm{H}_{2} \mathrm{O}$ can be formed via an activation energy of $0.51 \mathrm{eV}$, leading to an oxygen vacancy formation after water desorption. It is worth mentioning that even though the transition state structures of $\mathrm{O}-\mathrm{H}$ scission and $\mathrm{H}_{2} \mathrm{O}$ formation at the $\mathrm{OH}$-terminated interface are similar to those at the O-terminated interface, the activation energies increase at the $\mathrm{OH}$ $\mathrm{FeO} / \mathrm{Pt}$ interface since the hydrogen binding is weakened at these hydrogen-rich interfacial sites. From the plotted standard free energy profiles, one can see that the $\mathrm{C}-\mathrm{H}$ bond cleavage and water formation steps are probably the rate determining steps due to their relative high activation energies in the whole reaction cycle.

\subsection{Kinetic study of overall catalytic cycle}

After obtaining the reaction and activation energies of the catalytic cycle, we are now in the position of considering the reaction kinetics of the FeO/Pt bi-phase system. Generally, the reaction scheme can be described as follows: $\mathrm{O}_{2}$ and $\mathrm{CH}_{3} \mathrm{OH}$ adsorb on the surface, and the adsorbed $\mathrm{O}_{2} *$ dissociates into atomic $\mathrm{O} *$ species. Then the $\mathrm{CH}_{3} \mathrm{OH}^{*}$ decomposition occurs and leads to the formation of $\mathrm{CH}_{2} \mathrm{O}$; and the adsorbed $\mathrm{H}^{*}$ combine with $\mathrm{O} *$ to form $\mathrm{H}_{2} \mathrm{O}$ * Finally, 
the formed $\mathrm{CH}_{2} \mathrm{O}^{*}$ and $\mathrm{H}_{2} \mathrm{O}^{*}$ molecules desorb into the gas phase. The following approximation is taken in our kinetic model: The adsorption and desorption of $\mathrm{O}_{2}$ is considered to be in equilibrium, which can be combined as $\mathrm{O}_{2}+2^{*} \rightarrow 2 \mathrm{O}^{*}\left(\mathrm{X}^{*}\right.$ and $*$ are defined as the adsorbed $\mathrm{X}$ species and a surface free site, respectively). Likewise, the reactions of $\mathrm{CH}_{3} \mathrm{O} *+*$ $\rightarrow \mathrm{CH}_{2} \mathrm{O}^{*}+\mathrm{H}^{*}$ and $\mathrm{CH}_{2} \mathrm{O}^{*} \rightarrow \mathrm{CH}_{2} \mathrm{O}+*$ can be combined into $\mathrm{CH}_{3} \mathrm{O}^{*} \rightarrow \mathrm{CH}_{2} \mathrm{O}+\mathrm{H}^{*}$; the $\mathrm{OH}^{*}+\mathrm{H}^{*} \rightarrow \mathrm{H}_{2} \mathrm{O}^{*}+*$ and $\mathrm{H}_{2} \mathrm{O}^{*} \rightarrow \mathrm{H}_{2} \mathrm{O}+*$ can be combined into $\mathrm{OH}^{*}+\mathrm{H}^{*} \rightarrow \mathrm{H}_{2} \mathrm{O}+2^{*}$. The rate equation for each step is listed in Table S5, in which the rate constant of the forward (reverse) reaction can be derived from transition state theory ${ }^{57}$, as shown in (Eq2).

$$
k=\frac{k_{B} T}{h} e^{-\Delta G^{\neq, o} / k_{B} T}
$$

Where $k_{B}, h$, and $T$ represent the Boltzmann constant, Planck constant, and temperature in Kelvin. $\Delta G^{\neq, o}$ is the change of standard molar Gibbs free energy between the initial and transition state (i.e., energy barrier $E_{a}$ ). Moreover, to qualitatively determine the influence of single step to the overall reaction, the degree of rate control ${ }^{58}$, defined in $(\mathrm{Eq} 3)$, is calculated for each step.

$$
X_{R C, i}=\frac{k_{i}}{r}\left(\frac{\partial r}{\partial k_{i}}\right)_{k_{j \neq i}, K_{i}}=\left(\frac{\partial \operatorname{In} r}{\partial \operatorname{In} k_{i}}\right)_{k_{j \neq i}, K_{i}}
$$

where the partial derivative of the rate constants, $k_{j}$, is hold constant, for all other steps $j \neq i$. Rate constants $k_{i}$ and $k_{-i}$ will be varied by equal factors so that their ratio remains constant. In other words, $X_{R C, i}$ measures the variance of the overall rate when slightly changing the energy of transition state of step $i$. Typically, $X_{R C, i}$ should be positive, which means that the overall reaction will decrease while increasing the energy of transition state of step $i$. Larger $X_{R C, i}$ value means a bigger influence of step $i$ on the overall reaction, and the sum of all $X_{R C, i}$ should be unity.

A multi-site micro-kinetic model was employed in order to quantitatively determine the activity of the methanol partial oxidation at $500 \mathrm{~K}$ in our study (details see SI-14). Assuming that there are $10 \%$ interface sites (\#1) and $90 \%$ Pt flat sites (\#2), which is a quite reasonable assumption since the proportion of flat sites is normally larger than that of interfacial sites on the metal- 
supported oxide systems. We also tested different ratios of $\# 1 / \# 2$, showing no significant deviation on the kinetic trends. By testing and comparing the overall rates of pathway 1 and 2 (Table 2 and Table S10, respectively), we can confirmed that pathway 1 is much more favoured. In addition, we examined the performance of the catalyst when only Pt flat sites exist (i.e. without the $\mathrm{FeO} / \mathrm{Pt}$ interface, Table $\mathrm{S} 6$ ), in which the activation energy of $\mathrm{H}_{2} \mathrm{O}$ formation step is assumed to be zero for simplification. Some striking features can be obtained from the results of micro-kinetic modelling (Table 2, S7-S9). Firstly, we find that the exposed Fe sites of the interface are predominately covered by $\mathrm{OH}(9.97 \%$ out of $10 \%)$, which confirms the assumption of the interface will be an $\mathrm{OH}$-terminated interface under the reaction condition. Secondly, one can see from the tables that the production rate of $\mathrm{CH}_{2} \mathrm{O}$ at the $\mathrm{FeO} / \mathrm{Pt}$ interface (3.57E-04, Table 2) is many orders of magnitude higher than that on Pt flat surface (1.56E-16, Table S8), indicating that the $\mathrm{FeO} / \mathrm{Pt}$ interfaces indeed largely enhance the overall catalytic activity. Thirdly, the steps of $\mathrm{O}_{2}(\mathrm{~g})+2 \# 2_{2} \leftrightarrow 2 \mathrm{O}_{\# 2}$ and $\mathrm{H}_{\# 2}+\mathrm{OH}_{\# 1} \leftrightarrow \mathrm{H}_{2} \mathrm{O}(\mathrm{g})+\#_{1}+\#_{2}$ have the largest $\mathrm{X}_{\mathrm{RC}}$ value in $\mathrm{CH}_{3} \mathrm{OH}$ partial oxidation at the $\mathrm{FeO} / \mathrm{Pt}$ (-2.00 and 1.99, respectively), suggesting that they influence the reaction most.

Interestingly, the $\mathrm{X}_{\mathrm{RC}}$ of step $\mathrm{O}_{2}(\mathrm{~g})+2 \# 2 \leftrightarrow 2 \mathrm{O}_{\# 2}$ is negative, indicating that the overall reaction rate will be improved if increasing the energy barriers of $\mathrm{O}_{2}$ dissociative adsorption at the $\mathrm{Pt}$ flat sites. Such a case (negative $\mathrm{X}_{\mathrm{RC}}$ ) may be a special feature of multi-site catalysis. Although $\mathrm{O}_{2}$ dissociative adsorption has a lower energy barrier at the interface, the overall reaction network and site distribution make the interfacial oxygen primarily comes from $\mathrm{O}_{2}$ dissociative adsorption at the Pt flat sites (\#2) and surface diffusion (step 3 in Table 2), rather than directly dissociates at the $\mathrm{FeO} / \mathrm{Pt}$ interfacial sites. In other words, the oxygen prefers to dissociate at the Pt flat sites kinetically. The $\mathrm{CH}_{3} \mathrm{OH}^{*}, \mathrm{CH}_{3} \mathrm{O}^{*}$ and $\mathrm{H}^{*}$ species have a much lower coverage than the $\mathrm{O}^{*}$ species due to their large difference of binding energies at the Pt sites. Therefore, increasing the barrier of $\mathrm{O}_{2}$ dissociative adsorption at the Pt sites will make the adsorption of other intermediates more pronounced and eventually facilitate the overall reaction. For example, the ratio of adsorbed $\mathrm{CH}_{3} \mathrm{OH}^{*}$ and turnover frequency (TOF) will both go up by two orders, provided that the barrier of $\mathrm{O}_{2}$ dissociative adsorption increases by $0.25 \mathrm{eV}$. 
Finally, it is worth mentioning some implications of the general guidelines on catalyst design of the metal/oxide interfaces for efficient methanol partial oxidation. Firstly, increasing the barrier of oxygen dissociative adsorption on metal surfaces can be effectively improving the overall TOF, which may be achieved by using other metal substrates. Inert metals can be potential candidates as the metal substrates, such as $\mathrm{Ag}$ and $\mathrm{Au}$, which show a higher activation energy for oxygen dissociation ${ }^{59-61}$ and have a similar methanol binding $\operatorname{strength}^{62}(\sim-0.15 \mathrm{eV}$ in our tests) on their low Miller index surfaces. Secondly, a suitable binding strength of O* species is of significance to balance the oxygen adsorption $\left(1 / 2 \mathrm{O}_{2}+* \rightarrow \mathrm{O}^{*}\right)$ and its removal process $\left(\mathrm{OH}^{*}+\mathrm{H}^{*} \rightarrow \mathrm{H}_{2} \mathrm{O}+2 *\right)$, which is also applicable in other oxidation reaction on oxidebased catalysts. ${ }^{63-64}$ It is clear that the $\mathrm{O}^{*}$ binding strength at interface sites should be at least stronger than that at the sites of mono-phase constituent; otherwise, the interfacial $\mathrm{O} *$ will likely diffuse to the metal surface. On the contrary, too strong adsorption of $\mathrm{O}^{*}$ will hinder the formation of oxygen vacancy and eventually block the overall catalytic cycle. Typically, the binding strength of interfacial $\mathrm{O}^{*}$ species could possibly act as a descriptor for certain oxidation reaction in the metal/oxide bi-phase systems. Thirdly, the structural stability of metal/oxide interface is vital to guarantee its long-lasting work in practical operation. Although the thermal stabilities of different combination between oxide layers and support metals are not involved in our study, they can be evaluated by calculating the binding strength of $\mathrm{MO}_{\mathrm{x}}$ on the support metal, which has been extensively studied by Plessow and co-workers. ${ }^{65-66}$

\section{Conclusion}

In summary, this work is aimed at obtaining a comprehensive understanding of interfacial effects on catalytic reactions. The methanol partial oxidation $\left(\mathrm{CH}_{3} \mathrm{OH}+1 / 2 \mathrm{O}_{2} \rightarrow \mathrm{CH}_{2} \mathrm{O}+\mathrm{H}_{2} \mathrm{O}\right)$ at the $\mathrm{FeO} / \mathrm{Pt}$ interfaces was chosen as a model system to address in general how the interfacial sites promote a catalytic reaction. The methanol decomposition reaction on the $\mathrm{Fe}-\mathrm{FeO} / \mathrm{Pt}$, O$\mathrm{FeO} / \mathrm{Pt}$ interfaces and $\mathrm{Pt}(111)$ surface was studied in detail, in which two possible pathways and reaction barriers were calculated. The results regarding adsorption energies of reactants and activation barriers are summarized in the following: 
(i) The methanol adsorption energy on the flat $\mathrm{Pt}(111)$ surface is only $-0.23 \mathrm{eV}$, which is much weaker than the CUF site of $\mathrm{Fe}-\mathrm{FeO} / \mathrm{Pt}(-0.70 \mathrm{eV})$ and the $\mathrm{Pt}-\mathrm{O}$ ensemble of $\mathrm{O}-\mathrm{FeO} / \mathrm{Pt}$ interfaces $(-0.76 \sim-0.89 \mathrm{eV})$. The methanol binding strength at the Fe site $(-0.61 \mathrm{eV})$ would be weakened when the exposed $\mathrm{Fe}$ atom is oxidized.

(ii) At the $\mathrm{Fe}$ site of $\mathrm{Fe}-\mathrm{FeO} / \mathrm{Pt}$ interface, methanol decomposition requires to activate the O$\mathrm{H}$ and $\mathrm{C}-\mathrm{H}$ bonds via the activation energies of 0.46 and $1.16 \mathrm{eV}$, respectively, in pathway 1; while the reaction barriers of $\mathrm{C}-\mathrm{H}$ and $\mathrm{O}-\mathrm{H}$ bond breaking are 1.63 and $0.10 \mathrm{eV}$, respectively, in pathway2. Thus, at the $\mathrm{Fe}$ site of $\mathrm{FeO}$ ribbon, the activation energies of $\mathrm{C}$ $\mathrm{H}$ bond cleavage (over $1 \mathrm{eV}$ ) are too high for the methanol decomposition in both pathways.

(iii) On the $\mathrm{Pt}(111)$ surface, the $\mathrm{O}-\mathrm{H}$ and $\mathrm{C}-\mathrm{H}$ bond cleavage of methanol require to overcome the activation energies of 0.87 and $0.24 \mathrm{eV}$, respectively, in pathway 1 ; while the reaction barriers of C-H and $\mathrm{O}-\mathrm{H}$ bond breaking are 0.67 and $0.81 \mathrm{eV}$, respectively, in pathway2. It is clear that the large barriers of $\mathrm{O}-\mathrm{H}$ bond cleavage (over $0.8 \mathrm{eV}$ ) would hinder the methanol decomposition process at low temperatures.

(iv) At the Pt-O ensemble of $\mathrm{O}_{2 \mathrm{c}}-\mathrm{FeO} / \mathrm{Pt}$ interface, the $\mathrm{O}-\mathrm{H}$ and $\mathrm{C}-\mathrm{H}$ bond cleavage of methanol require to overcome activation energies of 0.04 and $0.17 \mathrm{eV}$, respectively, in pathway 1; the reaction barriers of $\mathrm{C}-\mathrm{H}$ and $\mathrm{O}-\mathrm{H}$ bond breaking are 0.68 and $0.03 \mathrm{eV}$, respectively, in pathway2. Remarkably, in pathway 1 , both steps of C-H and O-H bond cleavage could be facilitated via low activation barriers (below $0.2 \mathrm{eV}$ ), which could be rationalized that the $\mathrm{C}-\mathrm{H}$ and $\mathrm{O}-\mathrm{H}$ bond could be activated by interfacial $\mathrm{Pt}$ and $\mathrm{O}$ atoms, respectively.

By applying a multi-site micro-kinetic model, we obtain the following conclusions regarding the reaction process at the $\mathrm{FeO} / \mathrm{Pt}$ interfaces:

(i) The exposed $\mathrm{Fe}$ sites of the interface are predominately covered by $\mathrm{OH}^{*}$ species, while the Pt substrate is mainly covered by $\mathrm{O}^{*}$ species under the reaction condition. For the reactant adsorption, the methanol coverage is much higher at the $\mathrm{FeO} / \mathrm{Pt}$ interface than the $\mathrm{Pt}(111)$ flat surface. The overall reaction rate of methanol partial oxidation at the $\mathrm{FeO} / \mathrm{Pt}$ interface is dramatically faster than that on Pt mono-phase, showing significant advantages of 
interfacial sites.

(ii) The analyses of the degree of rate control $\mathrm{X}_{\mathrm{RC}}$ suggest the oxygen dissociative adsorption $\left(\mathrm{O}_{2}(\mathrm{~g})+2{ }_{\# 2} \leftrightarrow 2 \mathrm{O}_{\# 2}\right)$ and its removal steps $\left(\mathrm{H}_{\# 2}+\mathrm{OH}_{\# 1} \leftrightarrow \mathrm{H}_{2} \mathrm{O}(\mathrm{g})+\#_{11}+\#_{2}\right)$ should be the rate determining step. Furthermore, it is notable that the former step shows a negative $\mathrm{X}_{\mathrm{RC}}$ value, indicating the overall reaction will be faster when increasing the barriers of $\mathrm{O}_{2}$ dissociative adsorption on the flat Pt substrate, which might be a special feature in multiphase catalysis comparing to the mono-phase one.

Finally, based on the mechanistic and micro-kinetic studies on the $\mathrm{FeO} / \mathrm{Pt}$ system, we arrive at some simple guidelines with respect to further improving the performance of metal/oxide catalysts as follows:

(i) In metal/oxide systems, increasing the barrier of oxygen dissociative adsorption on the metal mono-phase by using other metal substrates, such as $\mathrm{Ag}$ and $\mathrm{Au}$, may give rise to higher activity of methanol partial oxidation.

(ii) Screening a better oxide/metal combination with suitable binding ability of interfacial oxygen species to balance the adsorption of oxygen and its removal process may be additionally beneficial to the systems. 


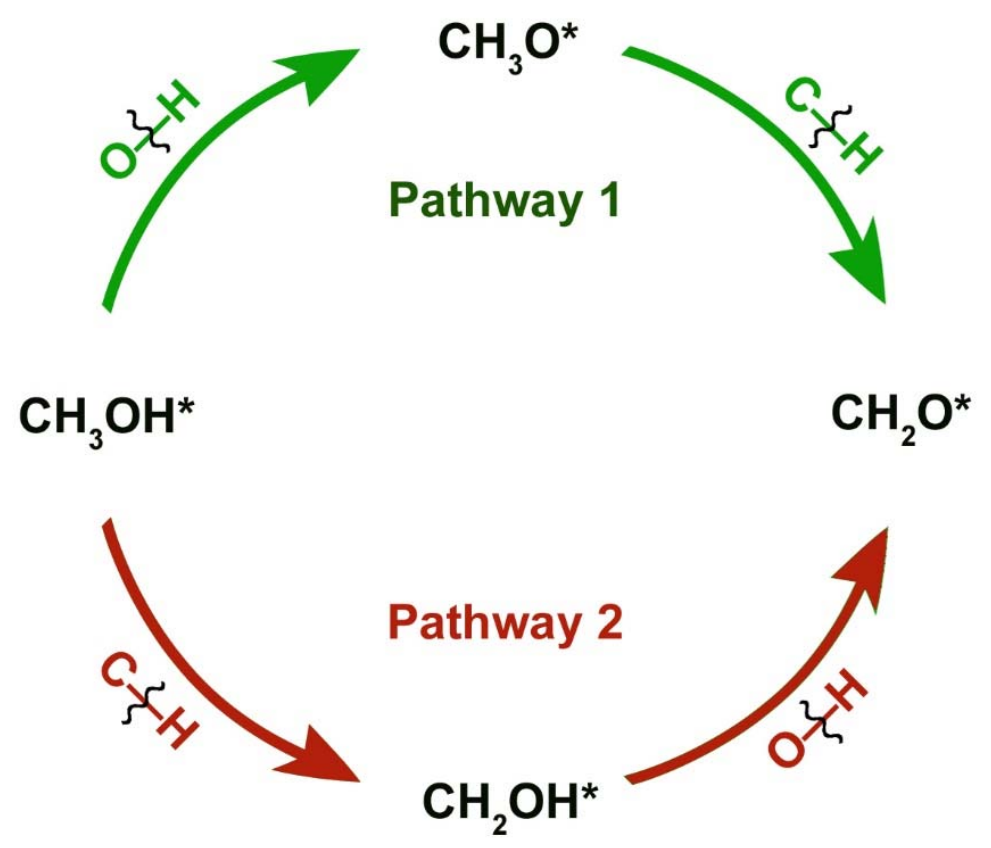

Scheme 1 Methanol decomposition pathways on the surface of catalysts. 
(a)

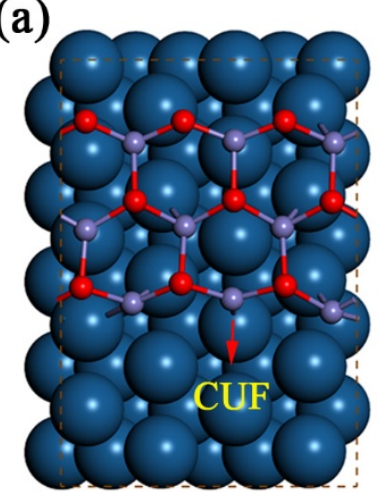

(c)

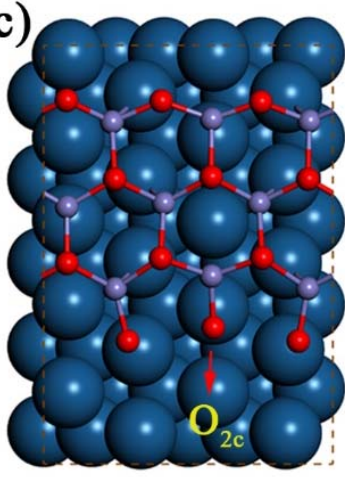

(b)

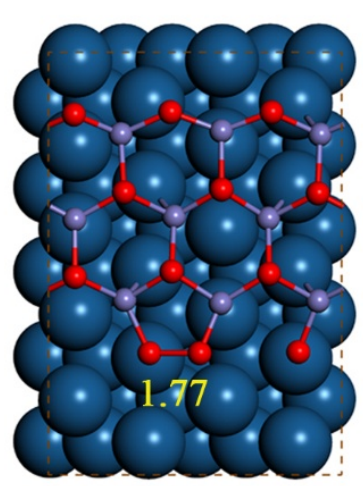

(d)

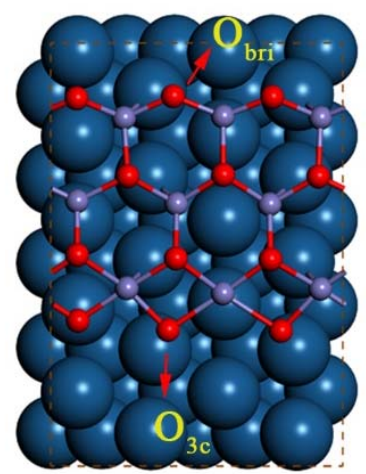

(e)



Fig. 1 Structures of $\mathrm{FeO} / \mathrm{Pt}$ interfaces. (a) Fe-terminated $\mathrm{FeO} / \mathrm{Pt}(111)$ interface with exposed CUF sites $(\mathrm{Fe}-\mathrm{FeO} / \mathrm{Pt})$; (b) transition state structure of $\mathrm{O}_{2}$ dissociation $(\mathrm{O}-\mathrm{O}$ distance is $1.77 \AA)$;

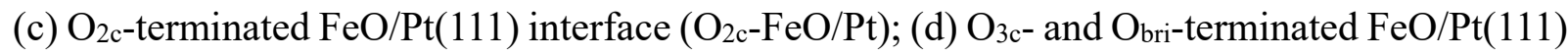
interfaces $\left(\mathrm{O}_{3 c^{-}}\right.$and $\mathrm{O}$ bri-FeO/Pt $)$; (e) transformation of Fe-terminated edge to the most stable Obri-terminated edge. Dark-blue balls represent for Pt atoms, purple for Fe and red for O. This notation is used throughout this paper. 
(a)

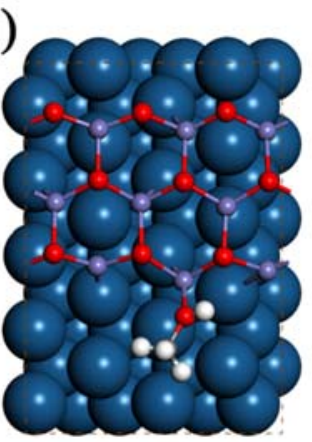

(b)

(d)

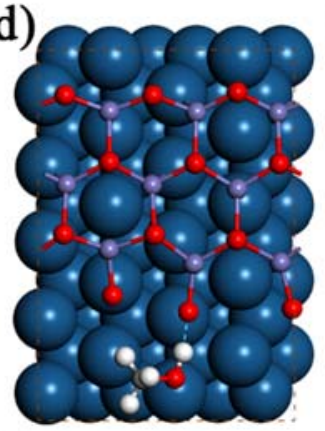

(e)

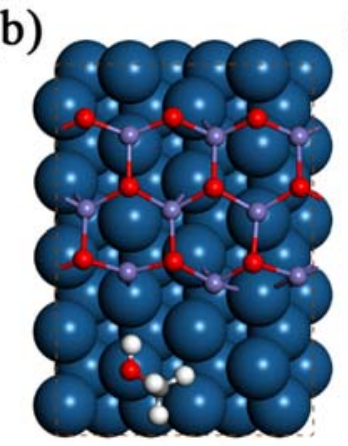

(g)

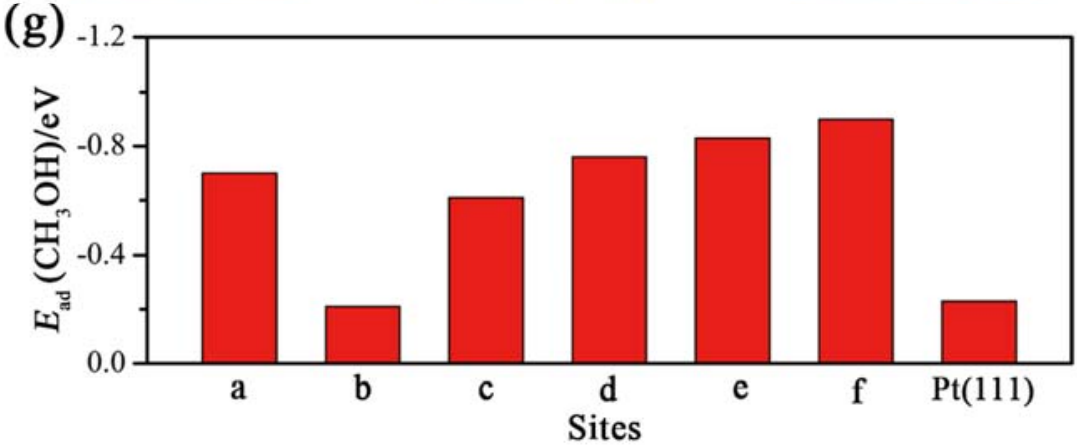

Fig. 2 Methanol adsorption at different sites of $\mathrm{FeO} / \mathrm{Pt}$ interfaces: (a) Fe site of $\mathrm{Fe}-\mathrm{FeO} / \mathrm{Pt}$; (b) $\mathrm{Pt}$ site of $\mathrm{Fe}-\mathrm{FeO} / \mathrm{Pt}$; (c) $\mathrm{Fe}$ site of $\mathrm{O}_{2 c}-\mathrm{FeO} / \mathrm{Pt}$; (d-f) Pt-O ensemble of $\mathrm{O}_{2 c^{-}}, \mathrm{O}_{3 c^{-}}$and $\mathrm{O}_{b r i}-\mathrm{FeO} / \mathrm{Pt}$ interfaces, respectively; (g) bar chart of methanol adsorption energies at (a-f) sites and $\operatorname{Pt}(111)$. Grey balls represent for $\mathrm{C}$ and white for $\mathrm{H}$. This notation is used throughout this paper. 

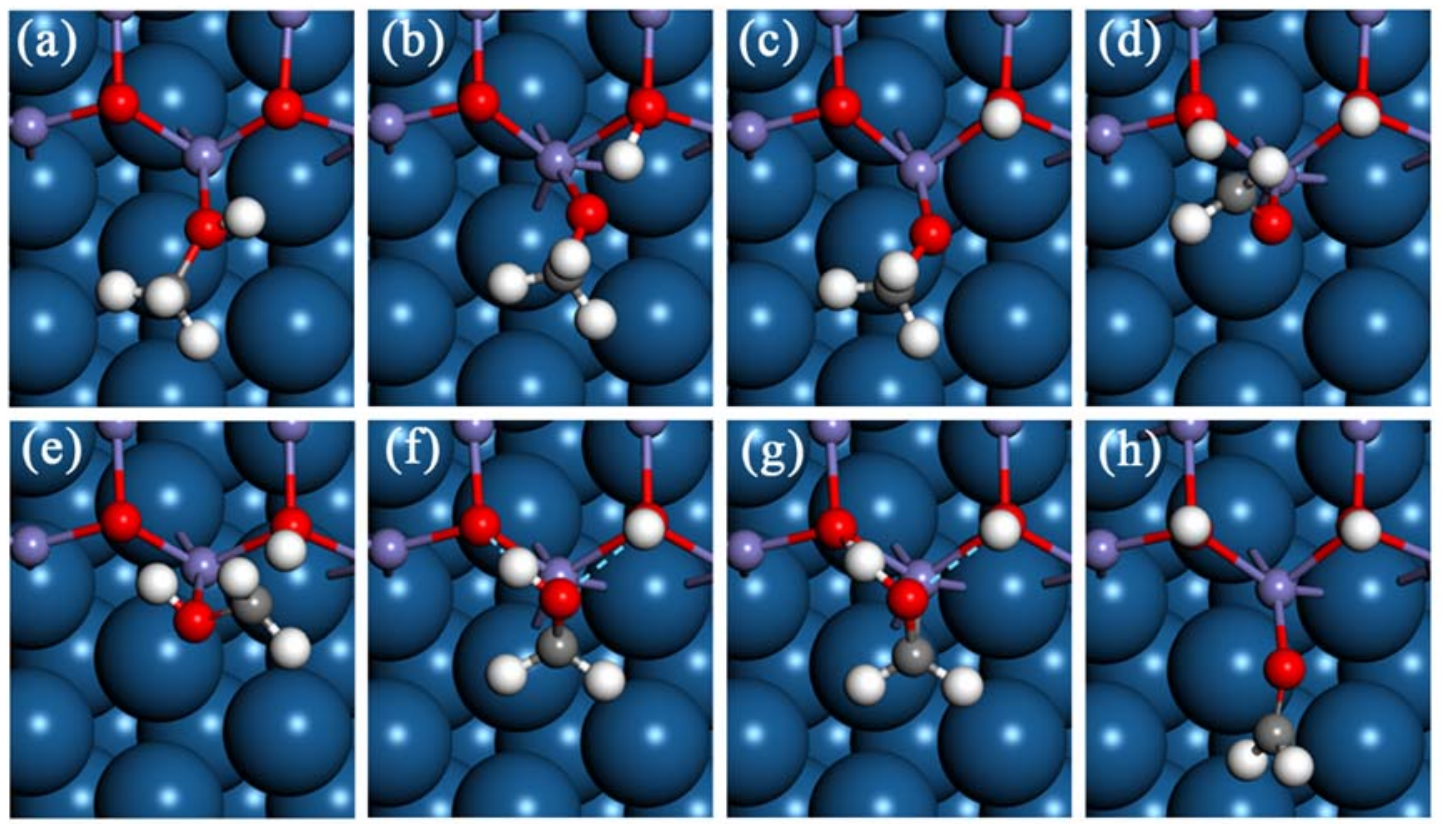

Fig. 3 Optimized structures of $\mathrm{CH}_{3} \mathrm{OH}$ decomposition on $\mathrm{Fe}-\mathrm{FeO} / \mathrm{Pt}$ interface: (a) $\mathrm{CH}_{3} \mathrm{OH}$ adsorption; (b-d) TS of O-H cleavage (TS1), intermediate state (IM) and TS of C-H cleavage (TS2) in pathway 1; (e-g) TS of C-H cleavage (TS1'), intermediate state (IM') and TS of O-H cleavage (TS2') in pathway 2; (h) $\mathrm{CH}_{2} \mathrm{O}$ adsorption. 

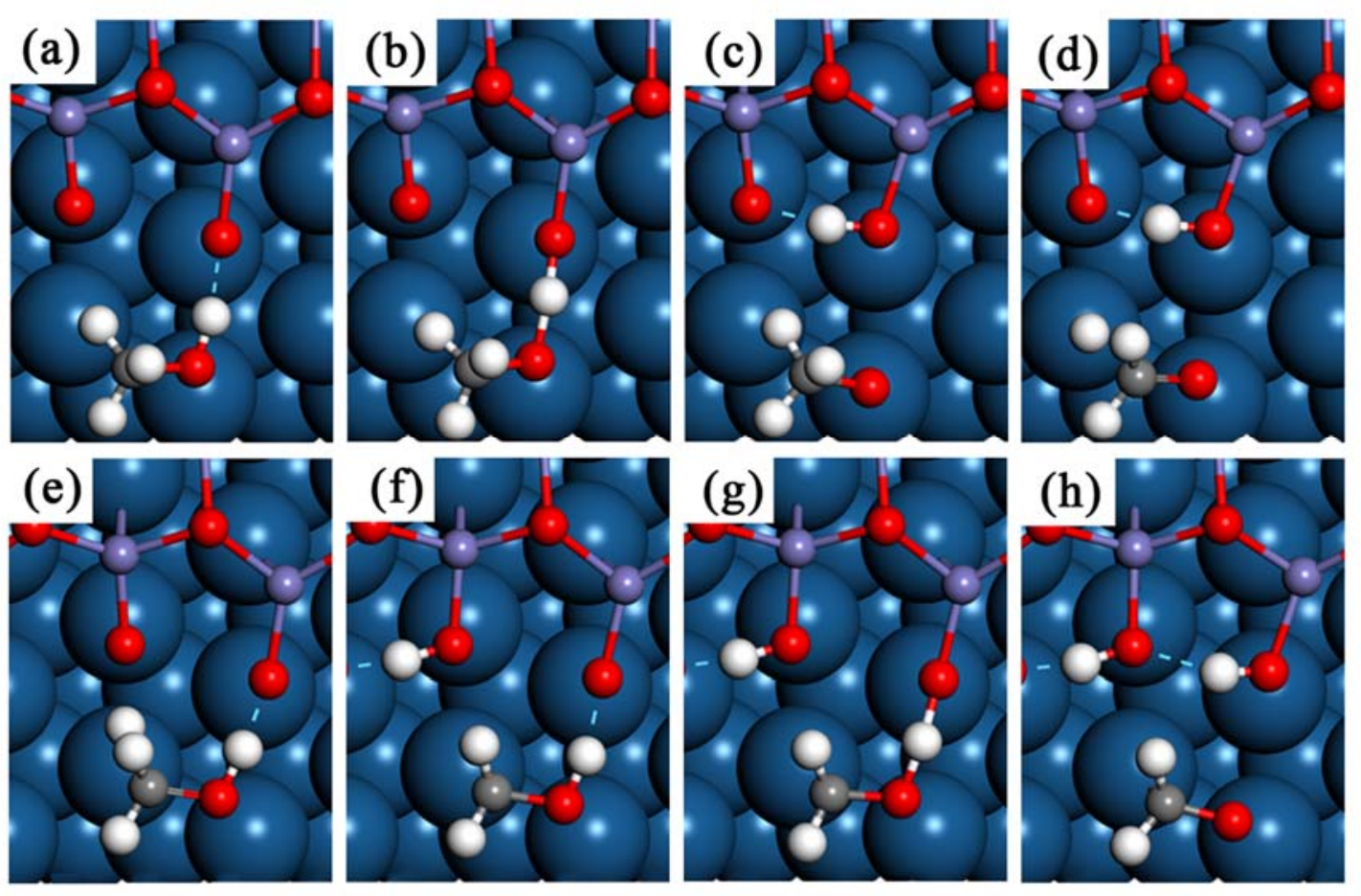

Fig. 4 Optimized structures of $\mathrm{CH}_{3} \mathrm{OH}$ decomposition on $\mathrm{O}_{2 \mathrm{c}}-\mathrm{FeO} / \mathrm{Pt}$ interface. (a) $\mathrm{CH}_{3} \mathrm{OH}$ adsorption; (b-d) structures in pathway 1, including the TS of O-H cleavage (TS1), intermediate state (IM) and TS of C-H cleavage (TS2); (e-g) structures in pathway 2, including the TS of C$\mathrm{H}$ cleavage (TS1'), intermediate state (IM') and TS of $\mathrm{O}-\mathrm{H}$ cleavage (TS2'); (h) $\mathrm{CH}_{2} \mathrm{O}$ adsorption. 


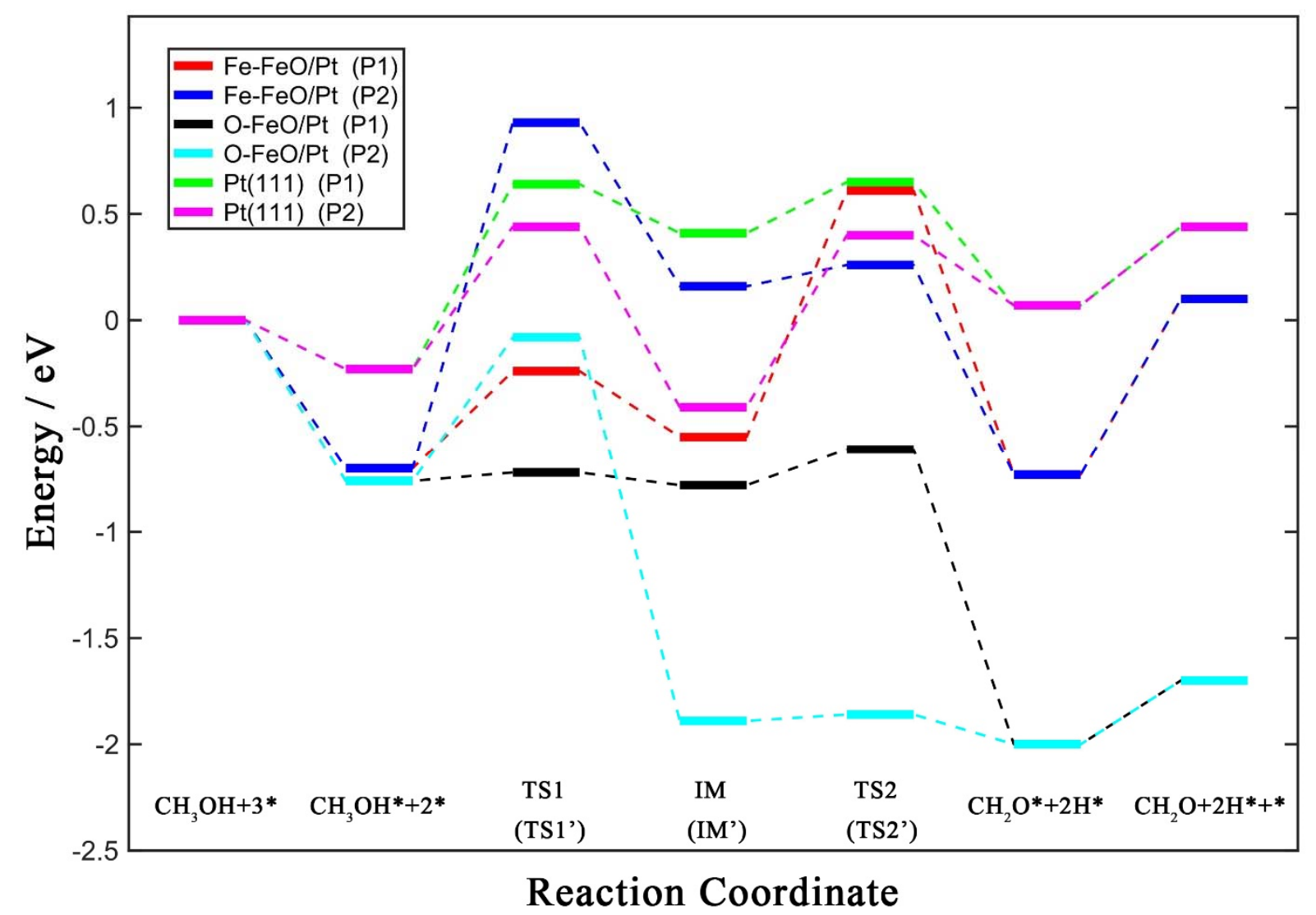

Fig. 5 Reaction profiles of methanol decomposition at the $\mathrm{Fe}-$ and $\mathrm{O}_{2 \mathrm{c}}-\mathrm{FeO} / \mathrm{Pt}$ interfaces and flat $\operatorname{Pt}(111)$ surface. In the final state, the formaldehyde desorbs to the gas phase, and the dissociated hydrogen adsorbs at the interfacial oxygen site of $\mathrm{FeO} / \mathrm{Pt}$ interface or the Pt site of $\mathrm{Pt}(111)$. The P1, P2 denote the pathway 1 and 2, respectively. 


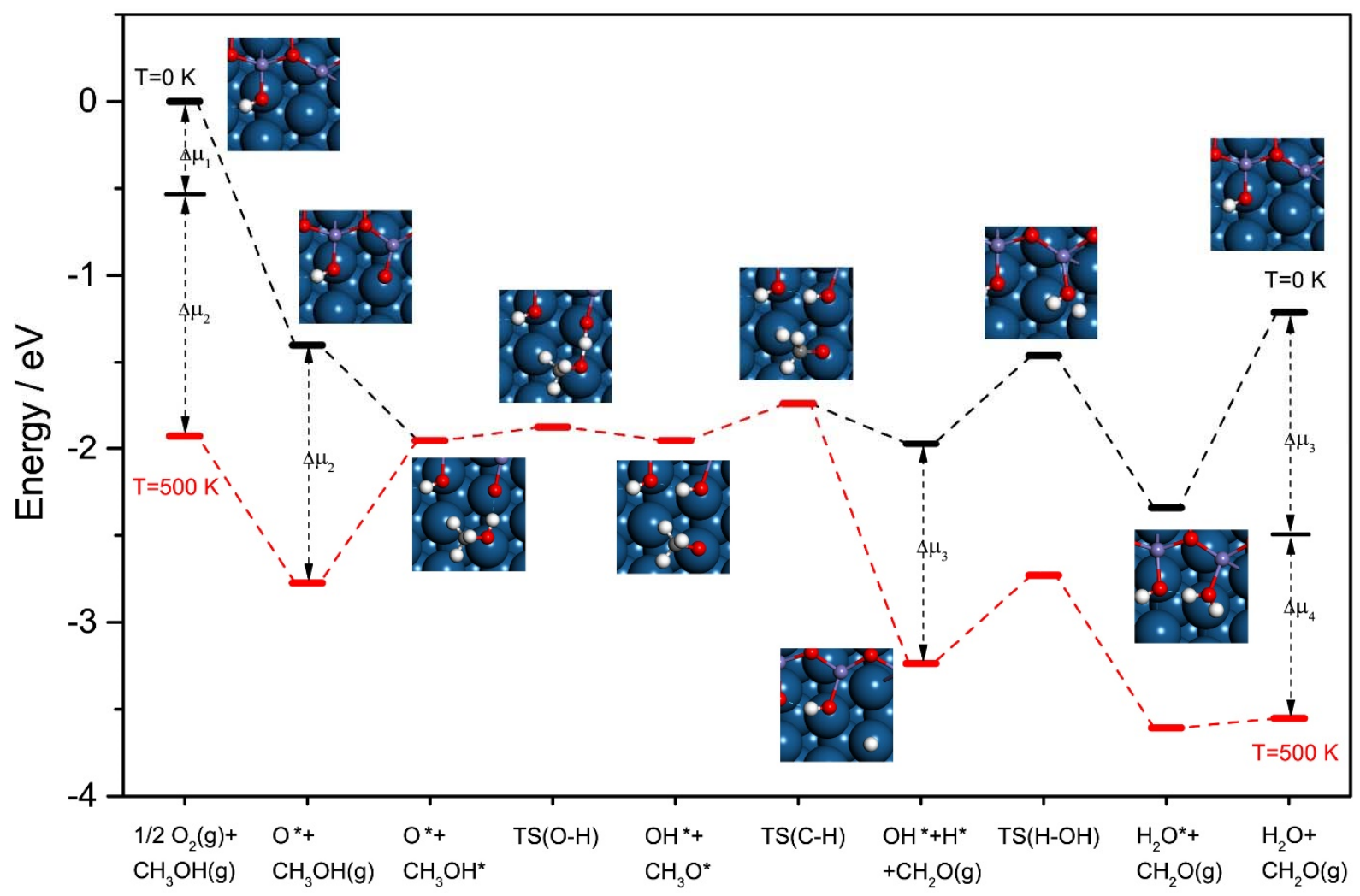

Fig. 6 The standard free energy profiles of methanol partial oxidation at the $\mathrm{OH}-\mathrm{FeO} / \mathrm{Pt}$ interface. The entropy effects of gas-phase $\mathrm{O}_{2}, \mathrm{CH}_{3} \mathrm{OH}, \mathrm{CH}_{2} \mathrm{O}$ and $\mathrm{H}_{2} \mathrm{O}$ are included $(T=500$ $\mathrm{K}$, the red line), in which $\Delta \mu_{1}=\frac{1}{2} T \Delta S_{\mathrm{O}_{2}}=0.55 \mathrm{eV} ; \Delta \mu_{2}=T \Delta S_{\mathrm{CH}_{3} \mathrm{OH}}=1.37 \mathrm{eV} ; \Delta \mu_{3}=$ $T \Delta S_{\mathrm{CH}_{2} \mathrm{O}}=1.27 \mathrm{eV} ; \Delta \mu_{4}=T \Delta S_{\mathrm{H}_{2} \mathrm{O}}=1.07 \mathrm{eV}$. The insets depict the detailed structures of the related state. 
Table 1 Reaction energies of methanol decomposition at the $\mathrm{FeO} / \mathrm{Pt}$ interface and $\mathrm{Pt}(111)$ surface. The unit is $\mathrm{eV}$.

\begin{tabular}{|c|c|c|c|c|c|c|}
\hline \multirow{2}{*}{ Reactions } & \multicolumn{2}{|c|}{$\mathrm{Fe}-\mathrm{FeO} / \mathrm{Pt}$} & \multicolumn{2}{|c|}{$\mathrm{O}-\mathrm{FeO} / \mathrm{Pt}$} & \multicolumn{2}{|c|}{$\operatorname{Pt}(111)$} \\
\hline & $E_{\mathrm{a}}$ & $\Delta E$ & $E_{\mathrm{a}}$ & $\Delta E$ & $E_{\mathrm{a}}$ & $\Delta E$ \\
\hline $\mathrm{CH}_{3} \mathrm{OH}+* \rightarrow \mathrm{CH}_{3} \mathrm{OH}^{*}$ & N/A & -0.70 & N/A & -0.76 & N/A & -0.23 \\
\hline \multicolumn{7}{|l|}{ Pathway 1} \\
\hline $\mathrm{CH}_{3} \mathrm{OH}^{*}+* \rightarrow \mathrm{CH}_{3} \mathrm{O}^{*}+\mathrm{H}^{*}$ & 0.46 & 0.15 & 0.04 & -0.02 & 0.87 & 0.64 \\
\hline $\mathrm{CH}_{3} \mathrm{O}^{*}+* \rightarrow \mathrm{CH}_{2} \mathrm{O}^{*}+\mathrm{H}^{*}$ & 1.16 & -0.18 & 0.17 & -1.22 & 0.24 & -0.34 \\
\hline \multicolumn{7}{|l|}{ Pathway 2} \\
\hline $\mathrm{CH}_{3} \mathrm{OH}^{*}+* \rightarrow \mathrm{CH}_{2} \mathrm{OH}^{*}+\mathrm{H}^{*}$ & 1.63 & 0.86 & 0.68 & -1.13 & 0.67 & -0.18 \\
\hline $\mathrm{CH}_{2} \mathrm{OH}^{*}+* \rightarrow \mathrm{CH}_{2} \mathrm{O}^{*}+\mathrm{H}^{*}$ & 0.10 & -0.89 & 0.03 & -0.11 & 0.81 & 0.49 \\
\hline $\mathrm{CH}_{2} \mathrm{O}^{*} \rightarrow \mathrm{CH}_{2} \mathrm{O}+*$ & N/A & 0.83 & N/A & 0.30 & N/A & 0.37 \\
\hline
\end{tabular}


Table 2 Forward $\left(r_{f}\right)$, backward $\left(r_{b}\right)$, overall $(r)$ reaction rates and degree of rate control $\left(\mathrm{X}_{\mathrm{RC}}\right)$ of each step of $\mathrm{CH}_{3} \mathrm{OH}$ partial oxidation at the $\mathrm{OH}-\mathrm{FeO} / \mathrm{Pt}$ interface.

\begin{tabular}{ccccc}
\hline Reactions & $r_{f}$ & $r_{b}$ & $r$ & $\mathrm{X}_{\mathrm{RC}}$ \\
\hline $\mathrm{O}_{2}(\mathrm{~g})+22_{\# 1} \leftrightarrow 2 \mathrm{O}_{\# 1}$ & $2.00 \mathrm{E}-09$ & $1.02 \mathrm{E}-13$ & $2.00 \mathrm{E}-09$ & $9.99 \mathrm{E}-01$ \\
$\mathrm{O}_{2}(\mathrm{~g})+22_{\# 2} \leftrightarrow 2 \mathrm{O}_{\# 2}$ & $1.79 \mathrm{E}-04$ & $9.12 \mathrm{E}-09$ & $1.79 \mathrm{E}-04$ & $-2.00 \mathrm{E}+00$ \\
$\mathrm{O}_{\# 2}+\# \leftrightarrow \mathrm{O}_{\# 1}+\# 2$ & $1.94 \mathrm{E}+03$ & $1.94 \mathrm{E}+03$ & $3.57 \mathrm{E}-04$ & $-3.69 \mathrm{E}-07$ \\
$\mathrm{CH}_{3} \mathrm{OH}(\mathrm{g})+\# 2 \leftrightarrow \mathrm{CH}_{3} \mathrm{OH}_{\# 2}$ & $2.77 \mathrm{E}+01$ & $2.77 \mathrm{E}+01$ & $3.57 \mathrm{E}-04$ & $8.79 \mathrm{E}-08$ \\
$\mathrm{CH}_{3} \mathrm{OH}_{\# 2}+\mathrm{O}_{\# 1} \leftrightarrow \mathrm{CH}_{3} \mathrm{O}_{\# 2}+\mathrm{OH}_{\# 1}$ & $1.27 \mathrm{E}-03$ & $9.18 \mathrm{E}-04$ & $3.57 \mathrm{E}-04$ & $1.91 \mathrm{E}-03$ \\
$\mathrm{CH}_{3} \mathrm{O}_{\# 2} \leftrightarrow \mathrm{CH}_{2} \mathrm{O}(\mathrm{g})+\mathrm{H}_{\# 2}$ & $3.57 \mathrm{E}-04$ & $1.92 \mathrm{E}-14$ & $3.57 \mathrm{E}-04$ & $4.90 \mathrm{E}-03$ \\
$\mathrm{H}_{\# 2}+\mathrm{OH}_{\# 1} \leftrightarrow \mathrm{H}_{2} \mathrm{O}(\mathrm{g})+\# 1+\# 2$ & $3.57 \mathrm{E}-04$ & $6.37 \mathrm{E}-10$ & $3.57 \mathrm{E}-04$ & $1.99 \mathrm{E}+00$ \\
\hline
\end{tabular}




\section{Supporting information}

The Supporting Information is available free of charge on the ACS Publications website:

- Additional tables and geometrical structures referred to in the main text.

- Additional micro-kinetic details referred to in the main text.

\section{Acknowledgements}

This project is support by National Natural Science Foundation of China (21333003, 21421004, 21303052, 21622305), National Key Basic Research Program of China (2013CB933201), Chen-Guang project (13CG24), Young Elite Scientist Sponsorship Program by CAST, Fundamental Research Funds for the Central Universities. Z. C. thanks the Chinese Scholarship Council for the abroad living support.

\section{References}

(1) Sachtler, W. M. H.; Backx, C.; Van Santen, R. A. Catal. Rev. 1981, 23, 127-149.

(2) Minahan, D. M.; Hoflund, G. B. J. Catal. 1996, 158, 109-115.

(3) Trovarelli, A. Catal. Rev. 1996, 38, 439-520.

(4) Kašpar, J.; Fornasiero, P.; Graziani, M. Catal. Today 1999, 50, 285-298.

(5) Jin, G.; Lu, G.; Guo, Y.; Guo, Y.; Wang, J.; Kong, W.; Liu, X. J. Mol. Catal. A: Chem. 2005, 232, 165-172.

(6) Gates, B. C. Chem. Rev. 1995, 95, 511-522.

(7) Chen, G.; Zhao, Y.; Fu, G.; Duchesne, P. N.; Gu, L.; Zheng, Y.; Weng, X.; Chen, M.; Zhang, P.; Pao, C.-W.; Lee, J.-F.; Zheng, N. Science 2014, 344, 495-499.

(8) Kattel, S.; Yan, B.; Yang, Y.; Chen, J. G.; Liu, P. J. Am. Chem. Soc. 2016, 138, 12440 12450.

(9) Mao, Y.; Chen, J.; Wang, H.; Hu, P. Chin. J. Catal. 2015, 36, 1596-1605.

(10) Sun, Y. N.; Qin, Z. H.; Lewandowski, M.; Carrasco, E.; Sterrer, M.; Shaikhutdinov, S.; Freund, H. J. J. Catal. 2009, 266, 359-368.

(11) Fu, Q.; Li, W.-X.; Yao, Y.; Liu, H.; Su, H.-Y.; Ma, D.; Gu, X.-K.; Chen, L.; Wang, Z.;

Zhang, H.; Wang, B.; Bao, X. Science 2010, 328, 1141-1144.

(12) Wang, Z.; Wang, H.-F.; Hu, P. Chem. Sci. 2015, 6, 5703-5711. 
(13) Meira, D. M.; Ribeiro, R. U.; Mathon, O.; Pascarelli, S.; Bueno, J. M. C.; Zanchet, D. Appl. Catal., B 2016, 197, 73-85.

(14) Zhao, G.; Yang, F.; Chen, Z.; Liu, Q.; Ji, Y.; Zhang, Y.; Niu, Z.; Mao, J.; Bao, X.; Hu, P.; Li, Y. Nat. Commun. 2017, 8, 14039.

(15) Rodriguez, J. A.; Ma, S.; Liu, P.; Hrbek, J.; Evans, J.; Pérez, M. Science 2007, 318, $1757-$ 1760.

(16) Suchorski, Y.; Wrobel, R.; Becker, S.; Weiss, H. J. Phys. Chem. C 2008, 112, 2001220017.

(17) Freund, H.-J.; Pacchioni, G. Chem. Soc. Rev. 2008, 37, 2224-2242.

(18) Ritter, M.; Ranke, W.; Weiss, W. Phys. Rev. B 1998, 57, 7240-7251.

(19) Giordano, L.; Pacchioni, G.; Goniakowski, J.; Nilius, N.; Rienks, E. D. L.; Freund, H.-J. Phys. Rev. B 2007, 76, 075416.

(20) Hagendorf, C.; Sachert, S.; Bochmann, B.; Kostov, K.; Widdra, W. Phys. Rev. B 2008, $77,075406$.

(21) Sachert, S.; Polzin, S.; Kostov, K.; Widdra, W. Phys. Rev. B 2010, 81, 195424.

(22) Sedona, F.; Rizzi, G. A.; Agnoli, S.; Llabrés i Xamena, F. X.; Papageorgiou, A.;

Ostermann, D.; Sambi, M.; Finetti, P.; Schierbaum, K.; Granozzi, G. J. Phys. Chem. B 2005, 109, 24411-24426.

(23) Barcaro, G.; Agnoli, S.; Sedona, F.; Rizzi, G. A.; Fortunelli, A.; Granozzi, G. J. Phys. Chem. C 2009, 113, 5721-5729.

(24) Meinel, K.; Eichler, A.; Schindler, K. M.; Neddermeyer, H. Surf. Sci. 2004, 562, 204218.

(25) Meinel, K.; Eichler, A.; Förster, S.; Schindler, K. M.; Neddermeyer, H.; Widdra, W. Phys. Rev. B 2006, 74, 235444.

(26) Allegretti, F.; Franchini, C.; Bayer, V.; Leitner, M.; Parteder, G.; Xu, B.; Fleming, A.;

Ramsey, M. G.; Podloucky, R.; Surnev, S.; Netzer, F. P. Phys. Rev. B 2007, 75, 224120.

(27) Franchini, C.; Podloucky, R.; Allegretti, F.; Li, F.; Parteder, G.; Surnev, S.; Netzer, F. P. Phys. Rev. B 2009, 79, 035420. 
(28) Allegretti, F.; Parteder, G.; Gragnaniello, L.; Surnev, S.; Netzer, F. P.; Barolo, A.; Agnoli,

S.; Granozzi, G.; Franchini, C.; Podloucky, R. Surf. Sci. 2010, 604, 529-534.

(29) Agnoli, S.; Sambi, M.; Granozzi, G.; Schoiswohl, J.; Surnev, S.; Netzer, F. P.; Ferrero,

M.; Ferrari, A. M.; Pisani, C. J. Phys. Chem. B 2005, 109, 17197-17204.

(30) Wu, C.; Marshall, M. S. J.; Castell, M. R. J. Phys. Chem. C 2011, 115, 8643-8652.

(31) Guimond, S.; Göbke, D.; Romanyshyn, Y.; Sturm, J. M.; Naschitzki, M.; Kuhlenbeck, H.; Freund, H.-J. J. Phys. Chem. C 2008, 112, 12363-12373.

(32) Gu, X.-K.; Ouyang, R.; Sun, D.; Su, H.-Y.; Li, W.-X. ChemSusChem 2012, 5, 871-878.

(33) Zeuthen, H.; Kudernatsch, W.; Merte, L. R.; Ono, L. K.; Lammich, L.; Besenbacher, F.; Wendt, S. ACS Nano 2015, 9, 573-583.

(34) Kudernatsch, W.; Peng, G.; Zeuthen, H.; Bai, Y.; Merte, L. R.; Lammich, L.;

Besenbacher, F.; Mavrikakis, M.; Wendt, S. ACS Nano 2015, 9, 7804-7814.

(35) Prada, S.; Giordano, L.; Pacchioni, G.; Noguera, C.; Goniakowski, J. J. Chem. Phys. 2014, 141, 144702.

(36) Greeley, J.; Mavrikakis, M. J. Am. Chem. Soc. 2002, 124, 7193-7201.

(37) Greeley, J.; Mavrikakis, M. J. Am. Chem. Soc. 2004, 126, 3910-3919.

(38) Zhong, W.; Liang, J.; Hu, W.; Cao, X.; Jia, C.; Jiang, J. Phys. Chem. Chem. Phys. 2016, $18,9969-9978$.

(39) Ivanov, K.; Dimitrov, D.; Boyanov, B. Chem. Eng. J. 2009, 154, 189-195.

(40) Macquarrie, D. Appl. Organomet. Chem. 2005, 19, 696-696.

(41) Dumesic, J. A. In The Microkinetics of Heterogeneous Catalysis. American Chemical Society: Washington, DC, 1993.

(42) Chen, J.-F.; Mao, Y.; Wang, H.-F.; Hu, P. ACS Catal. 2016, 6, 7078-7087.

(43) Perdew, J. P.; Burke, K.; Ernzerhof, M. Phys. Rev. Lett. 1996, 77, 3865-3868.

(44) Kresse, G.; Furthmüller, J. Comput. Mater. Sci. 1996, 6, 15-50.

(45) Kresse, G.; Furthmüller, J. Phys. Rev. B 1996, 54, 11169-11186.

(46) Kresse, G.; Joubert, D. Phys. Rev. B 1999, 59, 1758-1775.

(47) Blöchl, P. E.; Jepsen, O.; Andersen, O. K. Phys. Rev. B 1994, 49, 16223-16233. 
(48) Anisimov, V. I.; Zaanen, J.; Andersen, O. K. Phys. Rev. B 1991, 44, 943-954.

(49) Vladimir, I. A.; Aryasetiawan, F.; Lichtenstein, A. I. J. Phys.: Condens. Matter 1997, 9, 767-808.

(50) Spiridis, N.; Zając, M.; Piekarz, P.; Chumakov, A. I.; Freindl, K.; Goniakowski, J.;

Kozioł-Rachwał, A.; Parliński, K.; Ślęzak, M.; Ślęzak, T.; Wdowik, U. D.; Wilgocka-Ślęzak, D.; Korecki, J. Phys. Rev. Lett. 2015, 115, 186102.

(51) Alavi, A.; Hu, P.; Deutsch, T.; Silvestrelli, P. L.; Hutter, J. Phys. Rev. Lett. 1998, 80, $3650-3653$.

(52) Michaelides, A.; Hu, P. J. Am. Chem. Soc. 2001, 123, 4235-4242.

(53) Liu, Z.-P.; Hu, P. J. Am. Chem. Soc. 2003, 125, 1958-1967.

(54) Wang, G.-C.; Tao, S.-X.; Bu, X.-H. J. Catal. 2006, 244, 10-16.

(55) Cheng, J.; Hu, P.; Ellis, P.; French, S.; Kelly, G.; Lok, C. M. J. Phys. Chem. C 2008, 112, $1308-1311$.

(56) Cheng, J.; Hu, P. J. Am. Chem. Soc. 2008, 130, 10868-10869.

(57) Chorkendorff, I.; Niemantsverdriet, J. W. InConcepts of Modern Catalysis and Kinetics. Wiley-VCH: Weinheim, Germany, 2003.

(58) Stegelmann, C.; Andreasen, A.; Campbell, C. T. J. Am. Chem. Soc. 2009, 131, 80778082.

(59) Pulido, A.; Concepción, P.; Boronat, M.; Corma, A. J. Catal. 2012, 292, 138-147.

(60) Xu, Y.; Mavrikakis, M. J. Phys. Chem. B 2003, 107, 9298-9307.

(61) Parker, D. H.; Koel, B. E. J. Vac. Sci. Technol. A 1990, 8, 2585-2590.

(62) Liu, S.; Jin, P.; Zhang, D.; Hao, C.; Yang, X. Appl. Surf. Sci. 2013, 265, 443-451.

(63) Elias, J. S.; Artrith, N.; Bugnet, M.; Giordano, L.; Botton, G. A.; Kolpak, A. M.; ShaoHorn, Y. ACS Catal. 2016, 6, 1675-1679.

(64) Aryanpour, M.; Khetan, A.; Pitsch, H. ACS Catal. 2013, 3, 1253-1262.

(65) Plessow, P. N.; Bajdich, M.; Greene, J.; Vojvodic, A.; Abild-Pedersen, F. J. Phys. Chem. C 2016, 120, 10351-10360.

(66) Fester, J.; Bajdich, M.; Walton, A. S.; Sun, Z.; Plessow, P. N.; Vojvodic, A.; Lauritsen, J. 
V. Top. Catal. 2016, 1-10. 